\title{
Influence of Fluid Viscous Damper on the Dynamic Response of Suspension Bridge under Random Traffic Load
}

\author{
Yue Zhao $\left(\mathbb{D},{ }^{1}\right.$ Pingming Huang, ${ }^{1}$ Guanxu Long, ${ }^{1}$ Yangguang Yuan, ${ }^{2}$ and Yamin Sun ${ }^{3,4}$ \\ ${ }^{1}$ School of Highway, Chang'an University, Xi'an 710064, China \\ ${ }^{2}$ School of Civil Engineering, Xi'an University of Architecture and Technology, Xi'an 710055, China \\ ${ }^{3}$ School of Architecture and Civil Engineering, Xi'an University of Science and Technology, Xi'an 710054, China \\ ${ }^{4}$ Postdoctoral Research Station on Civil Engineering, Xi'an University of Science and Technology, Xi'an 710054, China \\ Correspondence should be addressed to Yue Zhao; unscmike@163.com
}

Received 30 October 2019; Accepted 24 April 2020; Published 26 May 2020

Academic Editor: Marco Corradi

Copyright (C) 2020 Yue Zhao et al. This is an open access article distributed under the Creative Commons Attribution License, which permits unrestricted use, distribution, and reproduction in any medium, provided the original work is properly cited.

\begin{abstract}
Fluid viscous dampers (FVDs) are widely used in long-span suspension bridges for earthquake resistance. To analyze efficiently the influences of FVDs on the dynamic response of a suspension bridge under high-intensity traffic flow, a bridge-vehicle coupling method optimized by isoparametric mapping and improved binary search in this work was first developed and validated. Afterwards, the traffic flow was simulated on the basis of monitored weigh-in-motion data. The dynamic responses of bridge were analyzed by the proposed method under different FVD parameters. Results showed that FVDs could positively affect bridge dynamic response under traffic flow. The maximum accumulative longitudinal girder displacement, longitudinal girder displacement, and longitudinal pylon acceleration decreased substantially, whereas the midspan girder bending moment, pylon bending moment, longitudinal pylon displacement, and suspender force were less affected. The control efficiency of maximum longitudinal girder displacement and accumulative girder displacement reached $33.67 \%$ and $57.71 \%$, longitudinal pylon acceleration and girder bending moment reached $31.51 \%$ and $7.14 \%$, and the pylon longitudinal displacement, pylon bending moment, and suspender force were less than $3 \%$. The increased damping coefficient and decreased velocity exponent can reduce the bridge dynamic response. However, when the velocity exponent was 0.1 , an excessive damping coefficient brought little improvement and may lead to high-intensity work under traffic flow, which will adversely affect component durability. The benefits of low velocity exponent also reduced when the damping coefficient was high enough, so if the velocity exponent has to be increased, the damping coefficient can be enlarged to fit with the velocity exponent. The installation of FVDs influences dynamic responses of bridge structures in daily operations and this issue warrants investigation. Thus, traffic load should be considered in FVD design because structural responses are perceptibly influenced by FVD parameters.
\end{abstract}

\section{Introduction}

FVDs were first used in the machinery and military industries. On account of their excellent energy dissipating capacity, they have been applied in structural vibration control under earthquakes. With structural vibration control as a key problem in safety operation of long-span bridges, FVDs are installed on many bridges to mitigate vibration and to serve as an effective seismic control device. In 1989, FVDs were first used on the Golden Bridge located in USA for increasing its seismic resistance. The identification test organized by the Highway Innovative Technology
Evaluation Center had been a valid reference in subsequent application and specification preparation of FVDs [1]. The technology was first brought to China on the Chongqing Egongyan Yangtze River Bridge in 2000 and is now widely used in Yangtze River bridges [2]. Since FVDs are integrated with the bridge, they have various complex effects on bridge responses, such as girder displacement, pylon bending moment, and expansion joint displacement. The designation of optimum FVD parameters focuses on the response under earthquake excitation and has been investigated comprehensively. The research methods generally included numerical analyses, shake table tests, and data monitoring 
[3-5]. Different techniques have been proposed by scholars to ascertain the optimal parameters that can achieve ideal structural response [6-8].

Although FVDs' effects under earthquake excitation have been widely studied, the dynamic responses of bridges, which are also vulnerable to vibrations excited by wind, temperature, and vehicles, have not been thoroughly examined. The most common dynamic response in the bridge life cycle is the frequent low-speed reciprocating motion, which is mainly caused by wind and traffic flow [9]. The corresponding service life of bridge accessories, such as expansion joints, is also influenced by this frequent reciprocating motion. FVDs can also absorb and dissipate energy imported from wind and traffic flow because of their dissipation capacity. The working conditions of supports, expansion joints, and suspenders can be improved by considering the daily longitudinal girder displacement in determining FVD parameters; the frequent reciprocating motion of main girder also can be effectively improved by using FVDs [10]. For a long-span bridge, the wind load may be more remarkable than vehicle load in transverse response of the bridge. Research shows that the dynamic responses of long-span suspension bridge under high winds and running trains are mainly influenced by strong winds when the wind is strong, but when the wind comes to low intensity, train load plays a decisive role in vertical displacement [11]. For the bridge dynamic response under wind and traffic flow, the wind load plays a major role in bridge lateral displacement. The vertical displacement is mainly controlled by the vehicle load [12]. Furthermore, scholars have made some studies on wind-induced vibration control and found that FVDs have different influences on various response indicators, which has an optimum interval for damping parameters $[13,14]$. In addition to the wind-induced vibration, the vehicle-induced vibration of long-span bridges is also remarkable and the influences of FVDs are still indistinct. The daily movement of bridge structures under social vehicles is an important factor related to bridge accessories' durability [5]. Varied structural response indexes present different variation trends with changing parameters of FVDs, such as accumulative girder displacement, girder midspan bending moment, pylon longitudinal acceleration, and pylon bending moment. The specific influences of FVDs on the dynamic response of long-span suspension bridges under traffic load, which can be further referenced in the optimization of FVD parameters, should hence be analyzed.

Because the traffic load of the highway bridge is a complicated random process with strong randomness of vehicle type, weight, and quantity, the calculation matrix of random traffic flow-bridge coupling analysis is huge and will take a lot of computing resources. Thus, a high efficiency random traffic flow-bridge analysis system needs to be established. The traditional vehicle-bridge coupling analysis system, which is based on a numerical method, mainly includes the modal superposition method and full coupling theory [15]. The modal superposition method is more simple and practical than the latter, but the high-order modes of structures are hard to obtain, thereby negatively affecting the calculation precision [16]. The full coupling analytical method has the advantages of clear physical meaning and high precision. However, this method requires huge amount of time and lots of computing resources when applied to long-span bridges under large and highly random traffic flow. This paper developed a vehicle-bridge interaction system with high efficiency to analyze the dynamic response of a bridge with FVDs under a large and highly random traffic flow. This system was established based on the interhistory iteration method and optimized by isoparametric mapping and improved binary search. Then, the traffic flow was simulated in accordance with the monitored data. Finally, the responses of the large-span bridge under traffic flow with different parameters of FVDs were studied.

\section{Establishment of Vehicle-Bridge Interaction System}

2.1. Finite Element Model of Bridge. The bridge model is established by the space truss model in ANSYS 15.0 [17]. Spine-beam, double-beam, and triple-beam models are widely used in the integral analysis of long-span bridges, and the grillage model and multiscale model are also used according to different requirements [18, 19]. Main cables and suspenders are usually simulated by the Link10 element, which can simulate the elasticity and plasticity of the structure. The pylon and girder are simplified into a twonode beam element and modeled by Beam 4 element. The railings and deck paving are simulated by the Mass 21 element. The entire structure is distributed into a number of elements and connected through the node on the boundary of adjacent elements. Given the demand for refined simulation of the vehicle-bridge interaction, a grillage model is utilized in this article to construct the prototype bridge to obtain detailed component response. The detailed information and feasibility of the model are proposed and validated in succeeding chapters.

2.2. Dynamic Vehicle Models. A vehicle is mainly composed of a car body, wheels, a shock mitigation system, and a damped system connecting different components. A vehicle dynamic model needs to be established before the vehiclebridge coupling analysis is conducted. With these demands, some hypothesis is unavoidable in constructing the dynamic models. The mass of damper and spring components are ignored compared with the quality of the vehicle body. Vehicle model is generally divided into different rigid bodies that are connected by axle mass blocks and by elastic and damped components. According to previous research, the common Chinese highway vehicles can be divided into 17 types of 5 categories in accordance with vehicle axle distance, axle number, axle load, and vehicle load based on weigh-inmotion data and Chinese automobile model manual [20, 21]. The vehicle classification is shown in Table 1.

The dynamic models are also provided based on different vehicle type. Taking three-axle vehicle as an example, the vehicle dynamic model of three-axle vehicle (double rear axle) is shown in Figure 1 [20]. The rigid body is usually deemed to have 6 degrees of freedom. As the vibration of the 
TABLe 1: Vehicle classification $[20,21]$.

\begin{tabular}{lccc}
\hline Type & Model number & Number of axles & Description \\
\hline T1 & V1, V2 & 2 & Sedan car and off-road vehicle \\
T2 & V3, V4 & 2 & Microbus and midsize truck \\
T3 & V5, V6 & 2 & Two-axle bus or truck \\
& V7 & 3 & Three-axle bus \\
T4 & V8 & 3 & Three-axle truck (double front axle) \\
& V9 & 3 & Three-axle truck (double rear axle) \\
& V11 & 4 & Four-axle truck \\
& V12 & 3 & Three-axle trailer \\
T5 & V13 & 4 & Four-axle trailer \\
& V14, V15 & 5 & Five-axle trailer (double front axle) \\
& V16, V17 & 5 & Five-axle trailer (triple front axle with different axle distance) \\
\end{tabular}

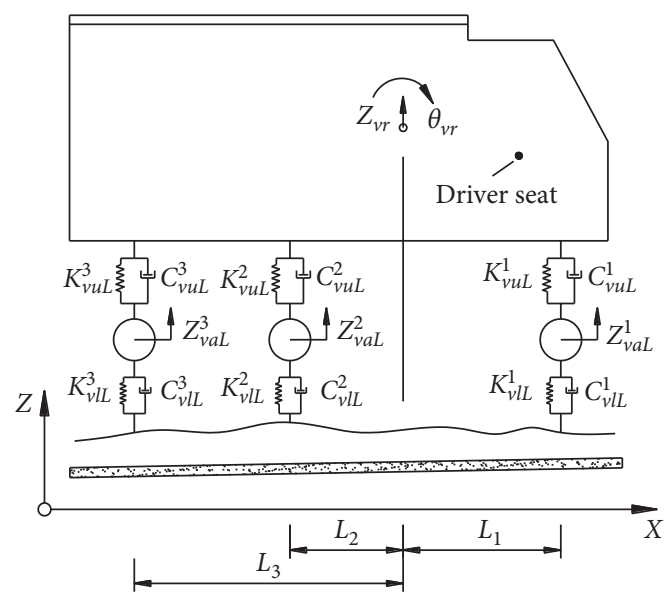

(a)

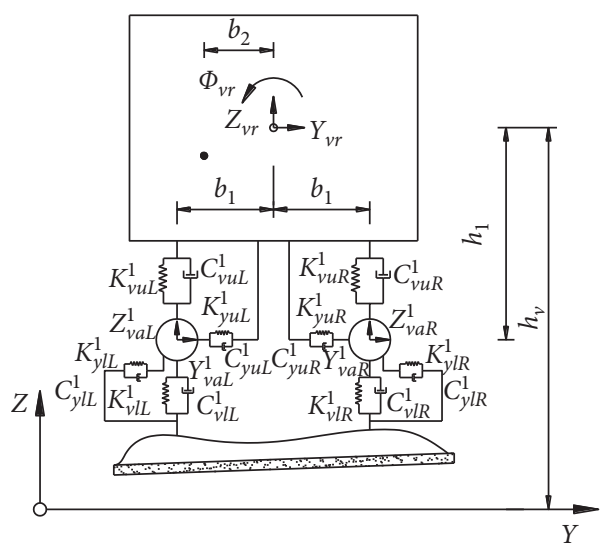

(b)

Figure 1: Dynamic analysis vehicle model of three-axle vehicle (double rear axle) [20].

vehicle in advancing direction is tiny compared to the distance travelled, the vibration of the vehicle body in advancing direction has few effects on the bridge. The bridge is mainly influenced by the integral movement of the vehicle in advancing direction. In order to reduce the complexity of vehicle model and the calculation, the degree of freedom in advancing is generally neglected in vehicle-bridge interaction analysis [22]. Thus, 5 degrees of freedom (vertical, horizontal, head nodding, side rolling, and head shaking) are considered for the integral vehicle. Each wheel has 2 degrees of freedom (vertical and horizontal). For the trailer, horizontal and head nodding degrees of freedom are neglected to derive the equation. Each vehicle body has 3 degrees of freedom, and each wheel has 1 degree of freedom.

\subsection{Load Distribution Based on Quadrilateral Isoparametric} Mapping. For the dynamic analysis under large random traffic flow, the positioning and loading of the contact point between the vehicle and the bridge should be a crucial issue. Bridge decks are typically simulated by grillage, solid, or shell elements in most models. The wheel load is simplified to a concentrated force acting on the bridge deck and then distributed to four adjacent nodes by four-node isoparametric mapping [23], which is the same as that of displacement in a two-dimensional plane, as shown in Figures 2 and 3.

The coordinate mapping equations are as follows:

$$
\left\{\begin{array}{l}
x=\sum_{i=1}^{4} N_{i}(\xi, \eta) x_{i}, \\
y=\sum_{i=1}^{4} N_{i}(\xi, \eta) y_{i}, \\
N_{i}(\xi, \eta)=\frac{1}{4}\left(1+\xi \xi_{i}\right)\left(1+\eta \eta_{i}\right),
\end{array}\right.
$$

where $x$ and $y$ denote the coordinates of the force point of the wheel load $P ; x_{i}$ and $y_{i}$ denote the $i_{\text {th }}$ quadrilateral element point's horizontal and vertical positions; $\xi$ and $\eta$ denote the corresponding values that $x$ and $y$ map from the quadrilateral element to the parent element; $\xi_{i}$ and $\eta_{i}$ denote known quantities, namely, the ith node's horizontal and vertical positions of the parent element; $N_{i}(\xi, \eta)$ denotes a function of isoparametric point $(\xi, \eta)$; function value $N_{i}$ denotes the $i_{\text {th }}$ quadrilateral element point's load distribution coefficient. 


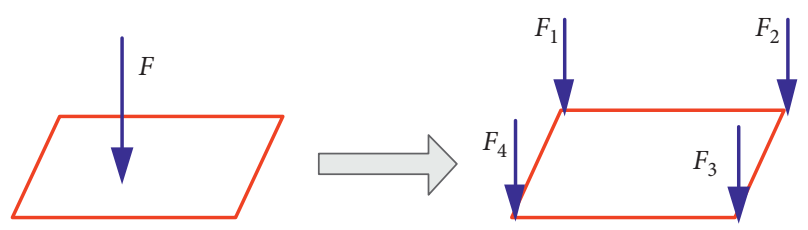

FIgURE 2: Contact point load distribution.

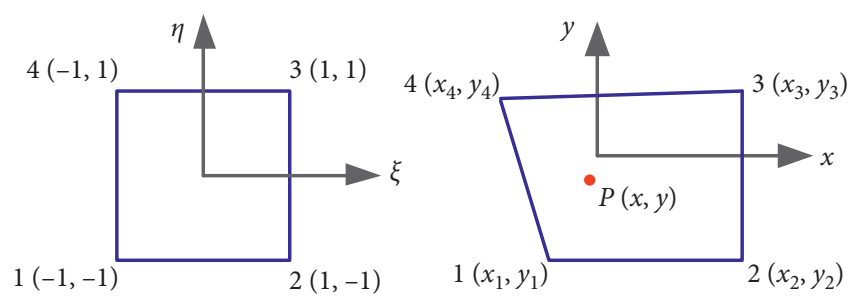

Figure 3: Isoparametric mapping.

The unknown quantities $\xi$ and $\eta$ of bilinear equation (1) can be solved by Newton iteration to obtain the distribution coefficient $N_{i}$. Afterwards, the automatic loading of the wheel load can be realized. The iteration process is as follows:

$$
\left\{\begin{array}{c}
{\left[\begin{array}{l}
\xi^{k+1} \\
\eta^{k+1}
\end{array}\right]=\left[\begin{array}{l}
\xi^{k} \\
\eta^{k}
\end{array}\right]-J\left(\xi^{k}, \eta^{k}\right)^{-1}\left[\begin{array}{l}
\sum_{i=1}^{4} N_{i}\left(\xi^{k}, \eta^{k}\right) x_{i}-x \\
\sum_{i=1}^{4} N_{i}\left(\xi^{k}, \eta^{k}\right) y_{i}-y
\end{array}\right],} \\
\mathbf{J}=\left[\begin{array}{l}
\left.\frac{\partial\left[\sum_{i=1}^{4} N_{i}(\xi, \eta) x_{i}\right]}{\partial \xi} \frac{\partial\left[\sum_{i=1}^{4} N_{i}(\xi, \eta) x_{i}\right]}{\partial \eta}\right] \\
\left.\frac{\partial\left[\sum_{i=1}^{4} N_{i}(\xi, \eta) y_{i}\right]}{\partial \xi} \frac{\partial\left[\sum_{i=1}^{4} N_{i}(\xi, \eta) y_{i}\right]}{\partial \eta}\right]
\end{array}\right.
\end{array}\right.
$$

where $\mathbf{J}$ denotes a Jacobian matrix; $\xi^{k}$ and $\eta^{k}$ denote the calculated value of the $k_{t h}$ iteration. The iteration is stopped when $\left\|\begin{array}{c}\xi^{k+1}-\xi^{k} \\ \eta^{k+1}-\eta^{k}\end{array}\right\|<\varepsilon$ with the iteration error $\varepsilon$ set to $10^{-8}$.

The position information of four adjacent nodes is indispensable for realizing the automatic loading of the wheel load $P$. Binary search can effectively halve the scope in finding specific elements in ordered arrays. Thus, it can be extended for searching the coordinate range of the wheel loading. For example, the process of searching the longitudinal wheel loading point $x$ is shown in Figure 4, and the positioning for the lateral loading point $y$ is the same.

The detailed steps are as follows.

(1) The node coordinates of the lane on which the vehicles drove are imported and sorted in ascending order to form a one-dimensional matrix.

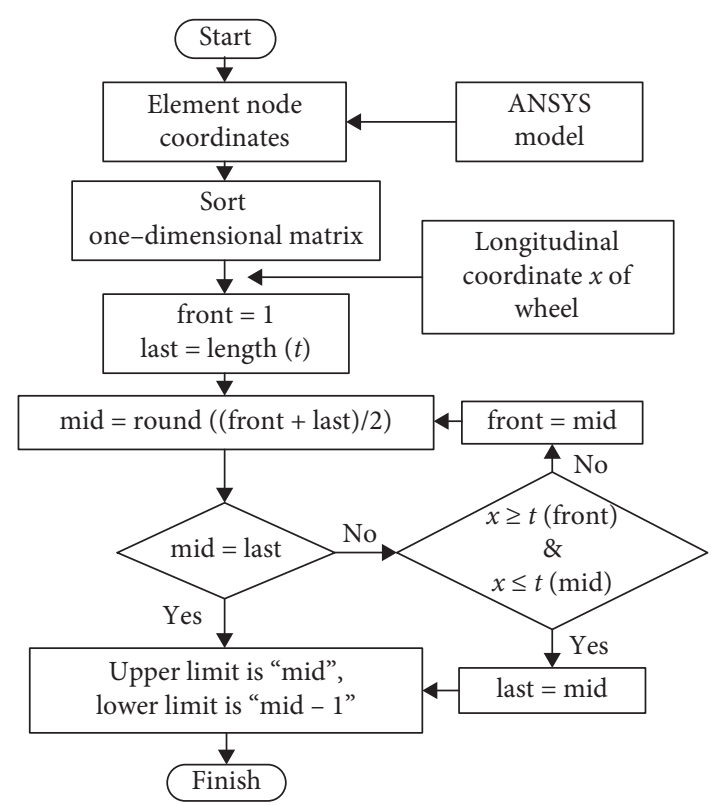

FIgURE 4: Flowchart of improved binary search.

(2) Initialization: the value of "front" is set to 1 ; the value of "last" is set to the number of columns of the matrix formed in step 1.

(3) Calculation of "mid": "mid" = "round"(("front" + "last")/2); "round" means rounding off.

(4) The search ends when "mid" = "last." The upper limit of the wheel $\mathrm{x}$-coordinate in the one-dimensional matrix is "mid," and the lower limit is "mid" -1 . Otherwise, whether the wheel $x$-coordinate is between "front" and "mid" is determined. If it happens, then "last" = "mid;" otherwise, "front" = "mid."

(5) Step 3 is executed until "mid" = "last."

Equation (1) can be solved by Newton iteration after finding four adjacent nodes of the wheel load $P$. Then, the interpolated coefficient at each node can be obtained to calculate the distribution load. In order to reduce the computation of bridge-vehicle coupling, only the results of displacement and velocity of load acting point are output. Afterwards, based on the known interpolated coefficient, the velocity and displacement of load acting point are calculated to solve the bridge-vehicle interaction force.

2.4. Road Surface Roughness. Road surface roughness is an important factor that could cause a vehicle's vertical vibration, which is directly related to the safety and comfort of the vehicle. Surface roughness can be described as an implementation of random processes and expressed by a power spectral density function. The recommended power spectral density function is adopted in this study [24]. The function $G_{d}(n)$ is expressed as

$$
G_{d}(n)=G_{d}\left(n_{0}\right)\left(\frac{n}{n_{0}}\right)^{-\omega}
$$


where $G_{d}(n)$ denotes the power spectral density function $\left(\mathrm{m}^{3} /\right.$ cycle $) ; n$ denotes spatial frequency per unit length $\left(\mathrm{m}^{-1}\right) ; n_{0}$ denotes reference spatial frequency, $n_{0}=0.1 \mathrm{~m}^{-1}$; $G_{d}\left(n_{0}\right)$ denotes power spectral density under reference spatial frequency; and $\omega$ denotes the frequency exponent, and $\omega=2$.

Road surface roughness is assumed to be a zero-mean stationary Gaussian random process. Thus, it can be generated through Fourier inversion as follows:

$$
r(x)=\sum_{k=1}^{N} \sqrt{2 G_{d}\left(n_{k}\right) \Delta n} \cos \left(2 \pi n_{k} x+\theta_{k}\right),
$$

where $\theta_{k}$ denotes the random phase angle uniformly distributed in $[0,2 \pi] ; n_{k}$ denotes the $k_{t h}$ reference spatial frequency.

The wheel-bridge relationship is assumed to be the point contact in constructing the vehicle-bridge interaction system. When the wheel comes into contact with the road surface, the vertical displacement of vehicle and bridge is the same and the bridge's vertical displacement is deemed additional surface roughness to the vehicle. Thus, the additional surface roughness caused by bridge displacement and road surface roughness is superposed to constitute the equivalent roughness which is inputted as the vertical excitation source. For the $i_{\text {th }}$ wheel, the formula considering bridge displacement is expressed as

$$
Z_{e}^{i}=Z_{b}^{i}+r_{i}(x)
$$

where $Z_{e}^{i}$ denotes the vertical equivalent roughness considering bridge displacement, $r_{i}(x)$ denotes the surface roughness at the wheel-bridge contact point, and $Z_{b}^{i}$ denotes the displacement at wheel-bridge contact point.

\subsection{Motion Equations of Vehicle-Bridge Interaction. The} interhistory iteration method is adopted to construct the highway vehicle-bridge coupling analysis system given the technique's remarkable efficiency under high-intensity traffic flow [25]. Unlike time step iteration, each step of the interhistory method involves full-time calculation. The bridge dynamic response under external load can be computed by any commercial analysis software with several iteration steps, thereby addressing the limitation of the programming calculation in the traditional method.

The bridge and vehicle dynamic equations can be expressed as follows:

$$
\left\{\begin{array}{l}
M_{v} \ddot{Z}_{v}+C_{v} \dot{Z}_{v}+K_{v} X_{v}=F_{v}, \\
M_{b} \ddot{Z}_{b}+C_{b} \dot{X}_{b}+K_{b} X_{b}=F_{b},
\end{array}\right.
$$

where $M_{v}, C_{v}$, and $K_{v}$ denote the global mass, damping, and stiffness matrices of the train subsystem, respectively; $M_{b}, C_{b}$, and $K_{b}$ denote the global mass, damping, and stiffness matrices of the bridge subsystem, respectively; $X_{v}$ and $X_{b}$ denote the displacement vectors of the train subsystem and the bridge subsystem, respectively; $\dot{Z}_{v}$ and $\ddot{Z}_{v}$ denote the velocity vector and acceleration vector of vehicle, respectively; $\dot{Z}_{b}$ and $\ddot{Z}_{b}$ denote the velocity vector and acceleration vector of bridge, respectively; and $F_{v}$ and $F_{b}$ denote the force vectors of vehicle and bridge, respectively.

Wheels are assumed to always be in contact with the bridge deck while the vehicle is moving, so the shock mitigation system and suspension system are deformed with bridge vertical deformation and surface roughness. The dynamic equations of the vehicle-bridge coupling system can be expressed as (7). The interaction force between the vehicle and the bridge is a function of vehicle motion, bridge motion, and road surface roughness stated by $Z_{v}, Z_{b}$, and $i$.

$$
\left\{\begin{array}{l}
F_{v}=F_{v i}\left(Z_{v}, \dot{Z}_{v}, \ddot{Z}_{v}, Z_{b}, \dot{Z}_{b}, \ddot{Z}_{b}, i\right), \\
F_{b}=F_{b i}\left(Z_{v}, \dot{Z}_{v}, \ddot{Z}_{v}, Z_{b}, \dot{Z}_{b}, \ddot{Z}_{b}, i\right) .
\end{array}\right.
$$

The coupling relationship between the vehicle and bridge subsystems is established by simultaneously solving (6) and (7) and then solved by the interhistory iteration method. The iteration process is realized by MATLAB R2014a [26], while the bridge model constructed in ANSYS 15.0 is used to output the bridge response. Each step of interhistory iteration for the bridge and the vehicle is separate and involves full-time calculation. Thus, the method will occupy reduced computer storage, generate accurate computations, and have the advantages of a clear aim and ease of operation. The convergence is checked by the interaction force between the vehicle and the bridge and defined as $\left\|F_{v}^{i}-F_{v}^{i-1}\right\|<0.1$. The detailed process is plotted in Figure 5.

\section{Validation of the Established Analysis System by Field Load Test}

3.1. Prototype Bridge and the FE Model. To validate the vehicle-bridge interaction analysis system and to analyze the influence of FVDs under random traffic flow, a three-dimensional finite element model of a long-span suspension bridge is constructed in ANSYS 15.0 as the research object (Figure 6). The bridge has a span of $896 \mathrm{~m}$, a steel truss main girder with the deck slab width of $26 \mathrm{~m}$, and a rigid central buckle. The detailed information of the bridge is as follows.

(1) The sag-span ratio of main cable is $1: 10$. The longitudinal distance in each suspender is $12.8 \mathrm{~m}$. The steel girder adopts warren truss stiffening beam with the height of $6.5 \mathrm{~m}$ and width of $26 \mathrm{~m}$, the minimum segment length is $6.4 \mathrm{~m}$, and the standard segment length is $12.8 \mathrm{~m}$. The pylon adopts a concrete portal frame structure. One pylon is $117.6 \mathrm{~m}$ high and another pylon is $122.2 \mathrm{~m}$ high.

(2) The main cable consists of 127 galvanized highstrength prefabricated parallel steel wire strands; each steel wire strand consists of 127 steel wires with a diameter of $5.1 \mathrm{~mm}$. Suspender is pin jointed with main cable and girder, and each consists of 91 galvanized high-strength prefabricated parallel steel wires with a diameter of $5.2 \mathrm{~mm}$.

(3) The material parameters have been modified according to the measured features of the bridge: elastic modulus of main cable is $1.94 \times 10^{11} \mathrm{~Pa}$, 


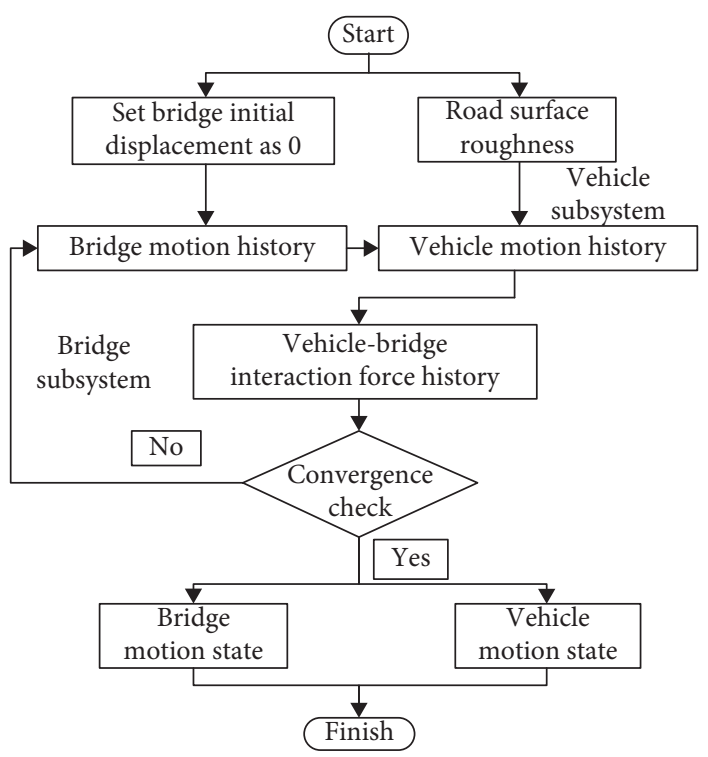

FIGURE 5: Flowchart of interhistory iteration.

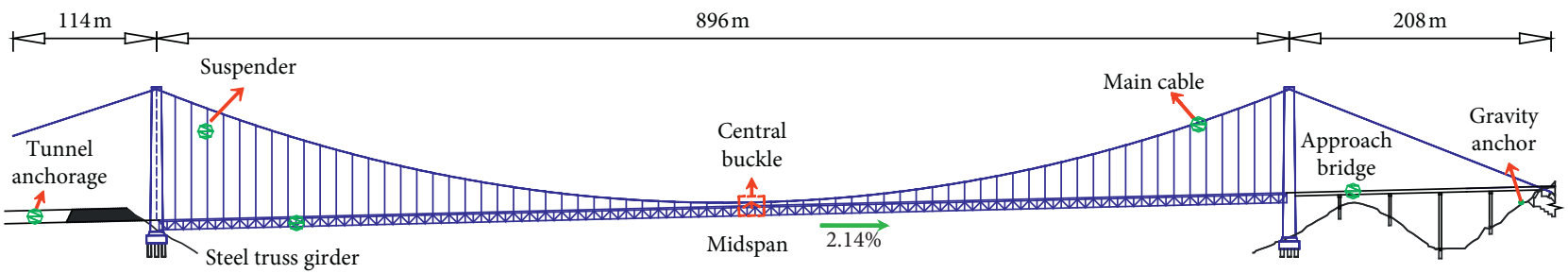

FIGURE 6: Information of bridge model (unit: (m)).

elastic modulus of girder is $2.13 \times 10^{11} \mathrm{~Pa}$, elastic modulus of pylon is $3.48 \times 10^{10} \mathrm{~Pa}$, the density of pylon is $2663 \mathrm{~kg} / \mathrm{m}^{3}$, the density of the truss element is $8646 \mathrm{~kg} / \mathrm{m}^{3}$, and the density of main cable is $8020 \mathrm{~kg} / \mathrm{m}^{3}$.

The pylon, central buckle, and main girder are modeled using Beam4 element. In order to simulate the lane load, four longitudinal girders were built in the model. Each lane load was exerted on the corresponding longitudinal girder. The main cables and suspenders are simulated using Link10 element, and the railings and deck paving are simulated using Mass21 element. The boundary conditions of the pylon foundation are simulated as fixed connection. The line displacement of the main cable at the anchorage point is constrained in three directions. The simulation of the vertex and tangential point of the cable saddle are realized through the node coupling. The vertical and horizontal displacement of the end of the girder is limited and the rotational degree of freedom is released.

The damping effect is an output resistive force that depends on the relative velocity of the damping device. Equation (8) is recommended to calculate the produced damping force [27]. FVDs are simulated using Combin 37 element. As shown in Figure 7, the FVDs are longitudinally settled on both sides of the midspan as a connection of the girder and the pylon, with two dampers on each side.

$$
F=K|v|^{\alpha} \operatorname{sign}(v),
$$

where $F$ denotes the damping force, $K$ denotes the damping coefficient, $v$ denotes the relative velocity between the ends of the damping device itself, sign denotes the sign function, and $\alpha$ denotes the velocity exponent.

The data of the bridge were collected when the prototype bridge just finished the construction. Existing research shows that the conditions of road surface roughness of new bridges in China are most A grade in accordance with ISO $8608[24,28]$. So the road surface roughness is set to A grade and generated based on specified parameters in ISO 8608 , as shown in Figure 8.

3.2. Accuracy Validation by Field Load Test. The numerical analysis result is compared with the result of dynamic experiment to verify the accuracy of the proposed method. The basis of the validation is the uniformity of theoretical model and actual bridge. Thus, the FE model in this article was constructed according to measured material properties and cable forces. Referring to existing researches, the accuracy of FE model can be considered as acceptable when the errors between the calculated and measured frequencies are less than $5 \%[29,30]$. The measured frequencies of the bridge are compared with the numerical results in Table 2 . It can be seen that the numerical results are comparable to the 


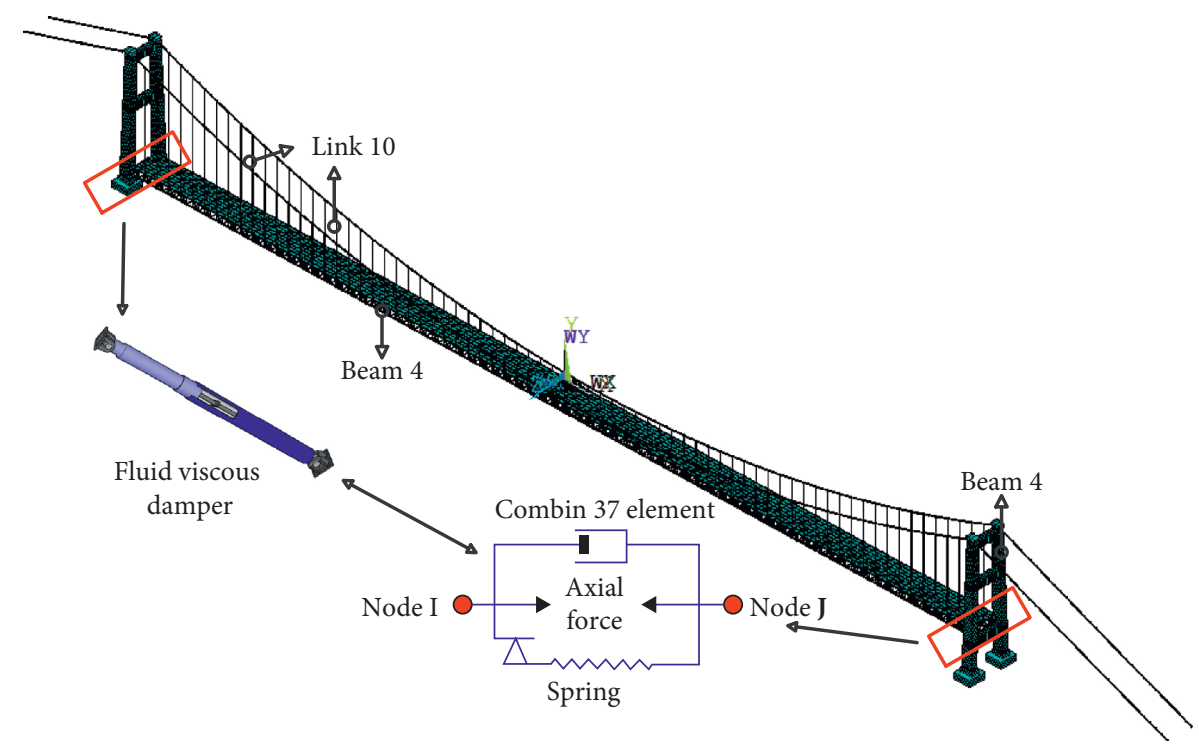

FIGURE 7: Information of bridge FE model.

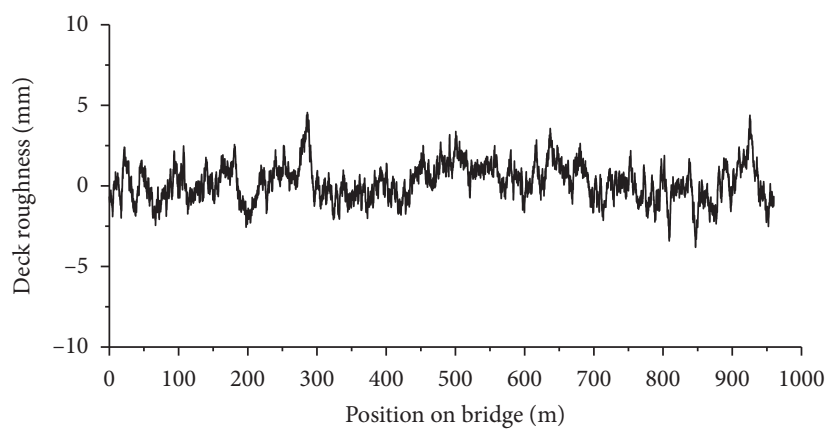

Figure 8: Road surface roughness of A grade.

TABLE 2: Comparison of the bridge frequencies.

\begin{tabular}{lcccc}
\hline Vibrating direction & Order & Measured result & Numerical result & Error (\%) \\
\hline \multirow{2}{*}{ Horizontal } & 1 & 0.071 & 0.07 & 0.175 \\
& 2 & 0.183 & 0.134 & 4.37 \\
& 1 & 0.131 & 0.182 & 2.29 \\
Vertical & 2 & 0.185 & 0.282 & 1.62 \\
& 3 & 0.292 & 0.38 & 3.42 \\
Torsional & 4 & 0.394 & 0.342 & 1.72 \\
& 1 & 0.348 & 0.425 & 2.07 \\
\hline
\end{tabular}

measured results. The maximum frequency error is $4.37 \%$ and all errors are less than 5\%, which proves the correctness of the FE model.

Then the dynamic strain and vertical acceleration of midspan are measured to validate the proposed method. The measuring point of the dynamic strain is set on the top chord of the steel trusses in the middle of midspan. The measuring point of vertical acceleration is set on the bridge deck at the same place.
The driving position of trucks and measuring points are shown in Figure 9; the detailed vehicle dynamic parameters are shown in Table 3 [31]. Three test conditions are settled for the validation: (1) two three-axle trucks passing through the bridge at a constant speed of $20 \mathrm{~km} / \mathrm{h}$, (2) two three-axle trucks passing through the bridge at a constant speed of $30 \mathrm{~km} / \mathrm{h}$, and (3) two three-axle trucks passing through the bridge at a constant speed of $50 \mathrm{~km} / \mathrm{h}$. 


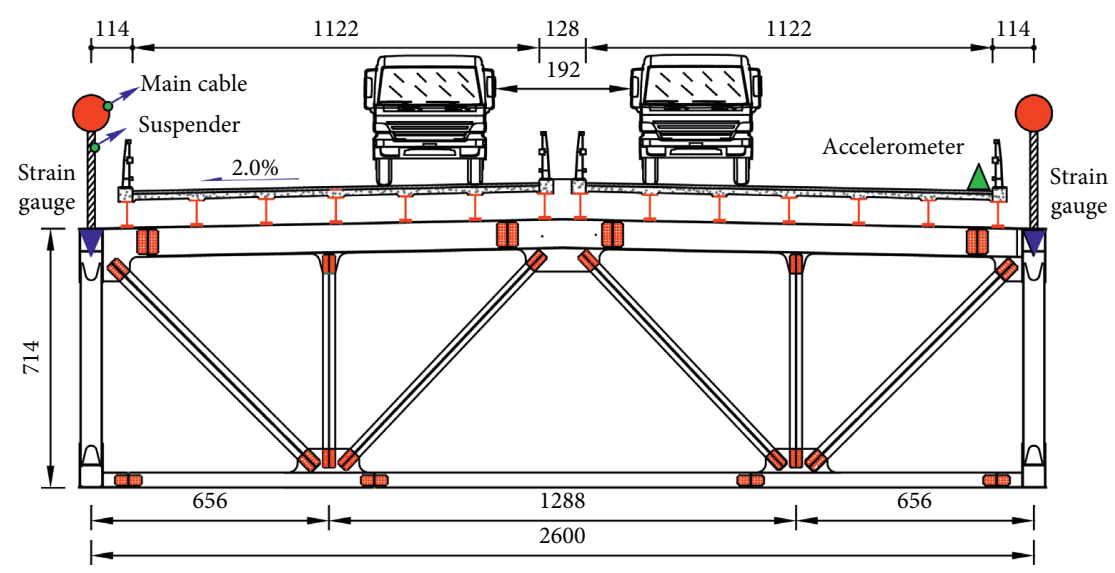

FIGURE 9: Information of bridge model and dynamic test (unit: $\mathrm{cm}$ ).

TABle 3: Technical parameters of the vehicle [31].

\begin{tabular}{lcccccc}
\hline Vehicle model & Axle number & $\begin{array}{c}\text { Axle } \\
\text { weight }(\mathrm{kg})\end{array}$ & $\begin{array}{c}\text { Upper stiffness } \\
\text { coefficient }(\mathrm{kN} / \mathrm{m})\end{array}$ & $\begin{array}{c}\text { Upper damping } \\
\text { coefficient }(\mathrm{kN} \cdot \mathrm{s} / \mathrm{m})\end{array}$ & $\begin{array}{c}\text { Lower stiffness } \\
\text { coefficient }(\mathrm{kN} / \mathrm{m})\end{array}$ & $\begin{array}{c}\text { Lower damping } \\
\text { coefficient }(\mathrm{kN} \cdot \mathrm{s} / \mathrm{m})\end{array}$ \\
\hline \multirow{3}{*}{ Three-axle truck } & Front axle & 8000 & 1577 & 26.6 & 3146 & 22.4 \\
& Middle axle & 13500 & 2362 & 20 & 2362 & 33.4 \\
& Rear axle & 13500 & 2362 & 20 & 2362 & 33.4 \\
\hline
\end{tabular}

The measured results are extracted and compared with those obtained by the analytical solution on the basis of the proposed method. The comparison of dynamic strain results under different vehicle velocities is shown in Figure 10. It can be seen that the changing trends of two curves are consistent in Figure 10. By comparison, the peak value of the dynamic strain of $50 \mathrm{~km} / \mathrm{h}$ is higher than $20 \mathrm{~km} / \mathrm{h}$ and $30 \mathrm{~km} / \mathrm{h}$. The peak value of measured dynamic strain of $50 \mathrm{~km} / \mathrm{h}$ is 30.03 while that of $20 \mathrm{~km} / \mathrm{h}$ and $30 \mathrm{~km} / \mathrm{h}$ is 26.6 and 27.9. It indicates that the maximum dynamic strain increases with the vehicle velocity. In Figure 10 (a), the error of peak values of two curves is $1.35 \%$. In Figure 10 (b), the error of peak values of two curves is $1.12 \%$. In Figure 10 (c), the error of peak values of two curves is $0.3 \%$. The comparison results indicate that the validity and accuracy of the proposed method are acceptable.

The midspan acceleration of measured result and the proposed method is shown in Figure 11. As the noise of measured acceleration is more obvious than that of strain and cannot be eliminated, the comparison of acceleration is not good as that of strain. But the variation trends of measured result and the proposed method are also consistent. The consistence of changing trends of the vertical acceleration also proves the accuracy of the proposed method.

\section{Traffic Flow Simulation Based on Monitored Data}

The response of long-span suspension bridges under traffic flow is mainly influenced by traffic flow density and total vehicle weight. The investigation focuses on the FVDs' influence on the bridge dynamic responses under traffic flow; thus the key variables are FVD parameters while the traffic flow needs to remain unchanged. Monitored traffic data gathered by weigh-in-motion system are processed to form typical traffic load to obtain the response of the studied structure [32]. The data collection site lies in Zhangjiawan bridge at the G104 highway in Zhejiang province of China, which is a coastal developed area. The vehicles include cars, vans, trucks, and trailers. The WIM data were measured in two lanes and collected more than 10,000 vehicles through one-month monitoring. In order to eliminate the sick data, the vehicles have low weight (less than $0.5 \mathrm{t}$ ) and high speed (more than $120 \mathrm{~km} / \mathrm{h}$ ) filtered in preprocessing the data coming from weigh-in-motion system.

First, the monitored data are statically initialized to separate vehicles in carriageway and passing lane according to the statistical property of lane distribution. As the statistical analysis in hours can reflect the randomness and the peak hours of traffic flow, hourly traffic flow is often used in traffic load analysis $[32,33]$. The WIM data were divided into 24 hours each day and the total vehicle weight of each period was calculated. For the bridge, the density of dynamic response is directly influenced by the external load. In order to obtain the most obvious response, the vehicles with maximum total vehicle weight in an hour are screened out as the basic data of the traffic flow. Figure 12 shows the maximum total vehicle weight of each hour in a month. The left road of two lanes of the advancing direction in China is passing lane and the right is carriageway. The maximum vehicle weights in an hour along the passing lane and the carriageway are $1115.31 \mathrm{t}$ and $759.78 \mathrm{t}$, respectively. The corresponding vehicle data are chosen as the basic data to simulate traffic flow. The detailed information of vehicle type is shown in Figure 13; it can be seen that the proportion of small and medium cars in traffic is larger than trucks. 


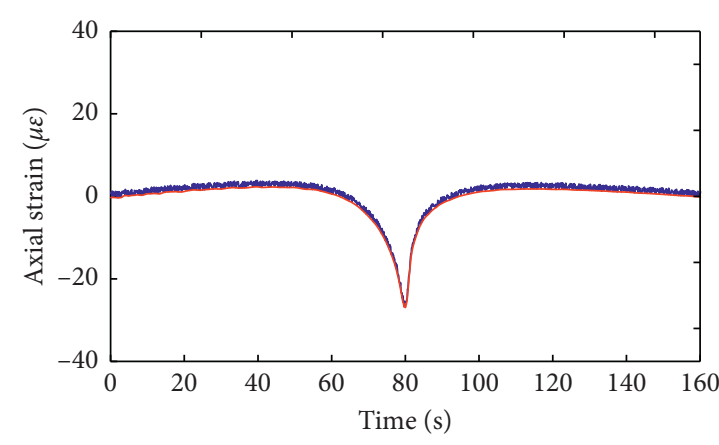

Measured result Proposed method

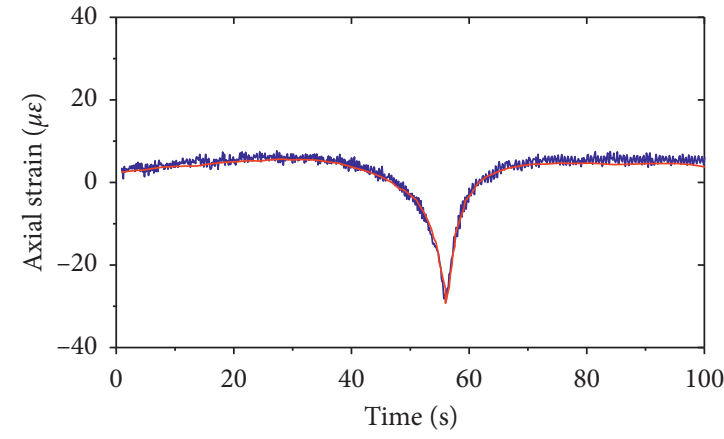

- Measured result

— Proposed method

(a)

(b)

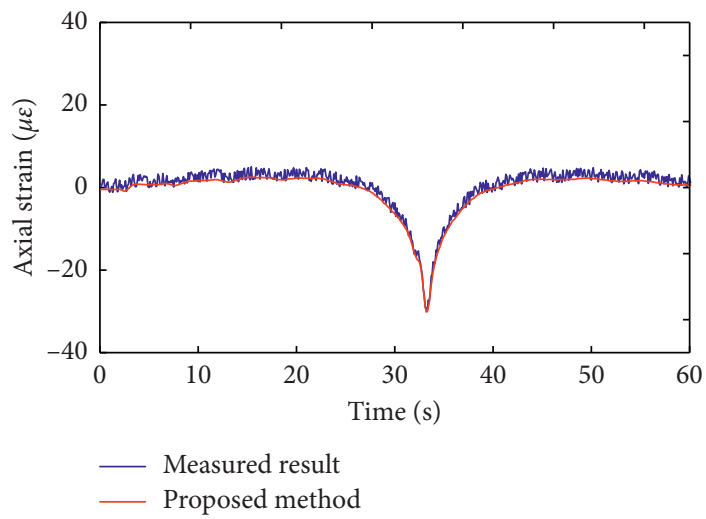

(c)

FIGURE 10: The comparison of dynamic strain results. (a) $20 \mathrm{~km} / \mathrm{h}$; (b) $30 \mathrm{~km} / \mathrm{h}$; (c) $50 \mathrm{~km} / \mathrm{h}$.

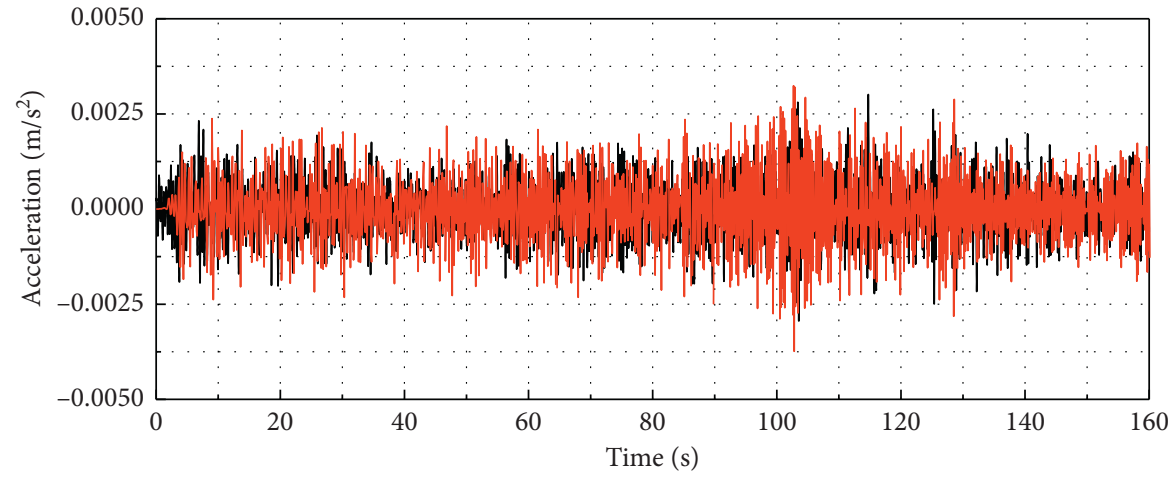

M
M Propured result
Proposed method

(a)

FIgUre 11: Continued. 


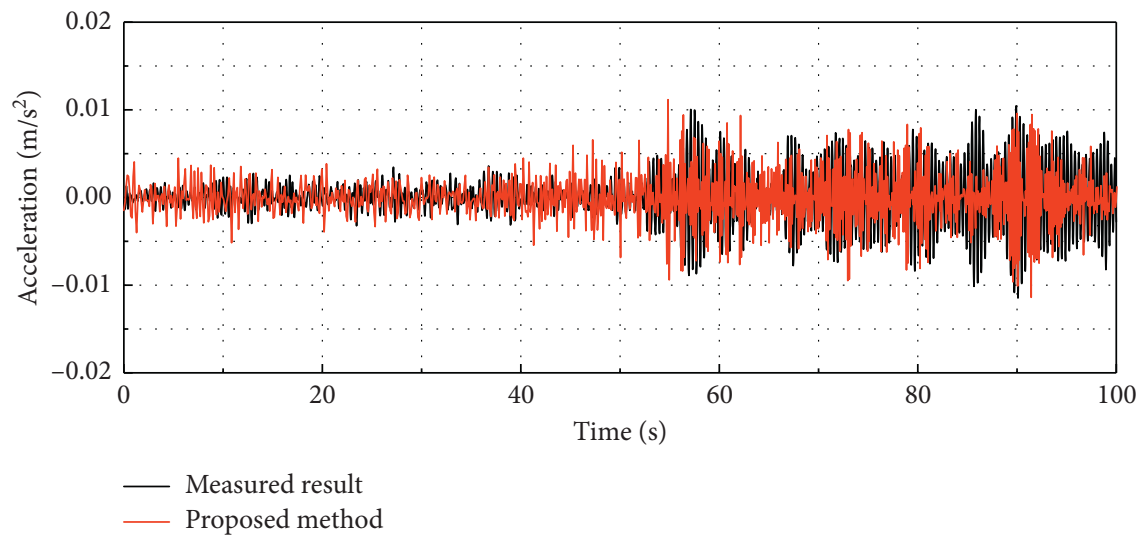

(b)

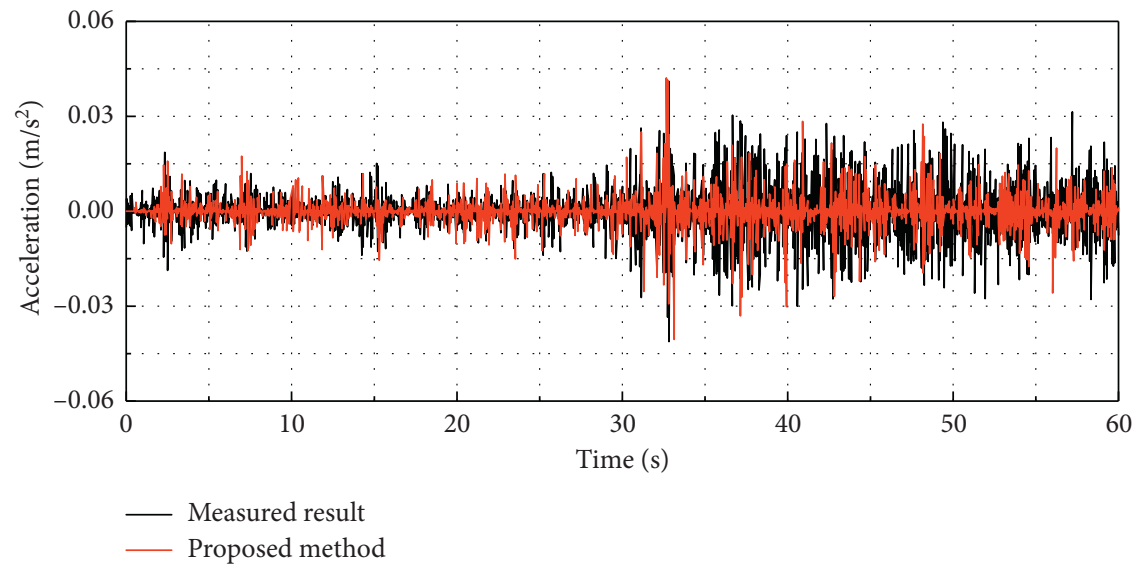

(c)

FIgURE 11: The comparison of midspan acceleration results. (a) Under $20 \mathrm{~km} / \mathrm{h}$; (b) under $30 \mathrm{~km} / \mathrm{h}$; (c) under $50 \mathrm{~km} / \mathrm{h}$.

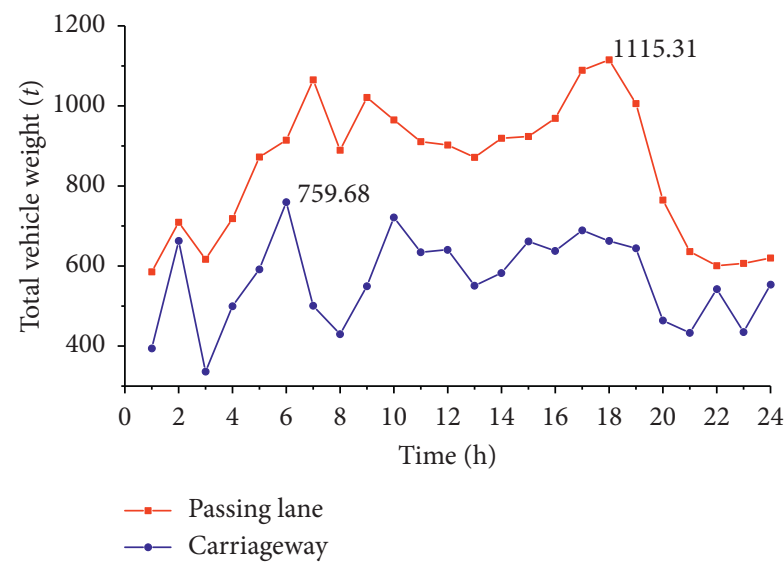

Figure 12: Extreme value of vehicle weight in hours.

The detailed simulation process is shown in Figure 14. As the prototype bridge is bidirectional with four lanes and the monitored data only have two lanes, the chosen vehicle data

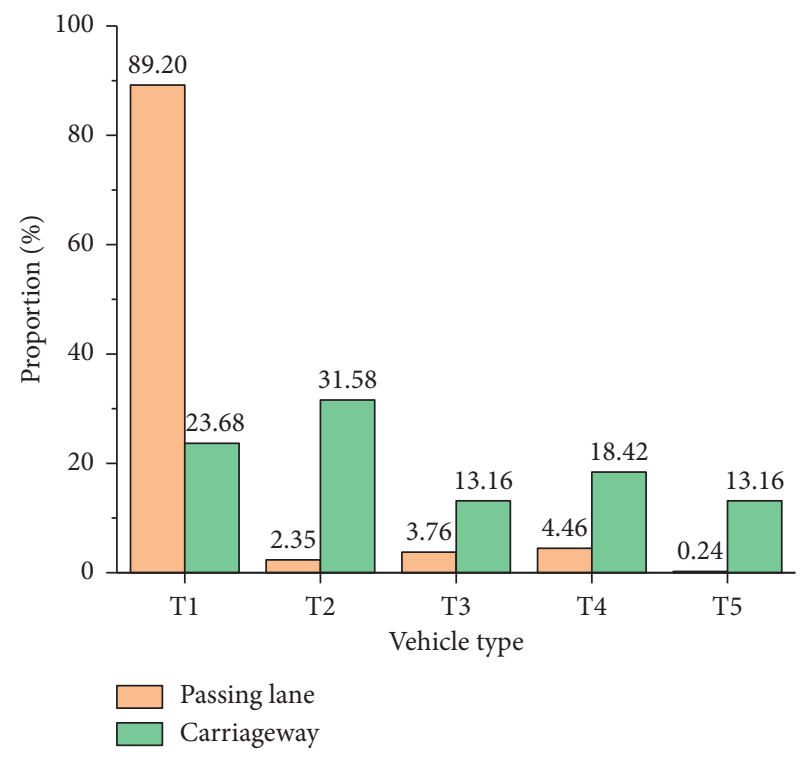

FIgURE 13: The vehicle type of selected data. 


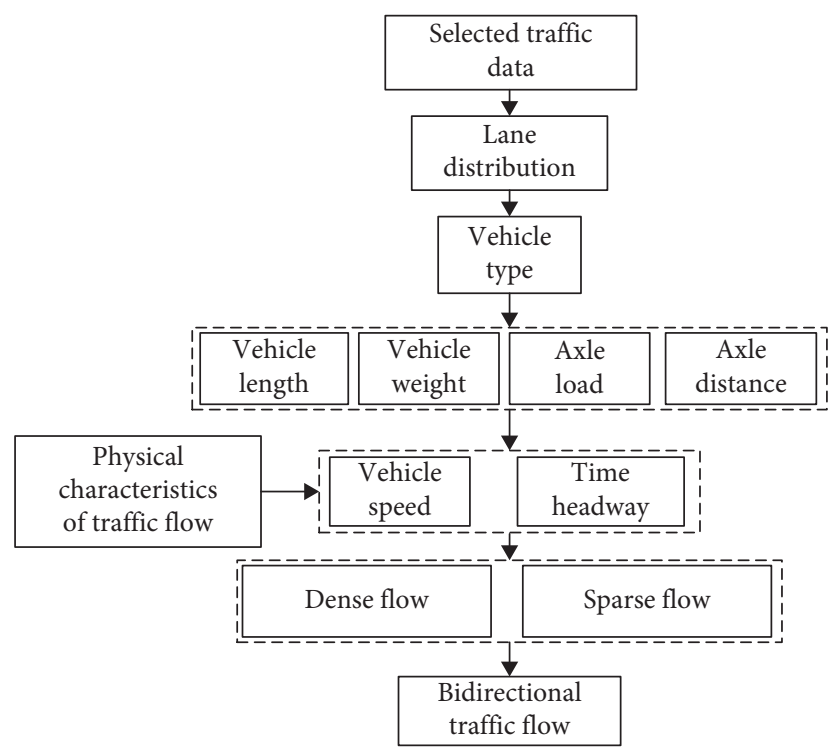

FIGURE 14: Flowchart of traffic flow generating.

TABle 4: Parameters of vehicle headway.

\begin{tabular}{|c|c|c|c|c|}
\hline \multirow{2}{*}{ Operation state } & \multirow{2}{*}{ Distribution type } & \multirow{2}{*}{ Lane } & \multicolumn{2}{|c|}{ Distribution parameters } \\
\hline & & & $\alpha$ & $\beta$ \\
\hline \multirow{2}{*}{ Sparse flow } & \multirow{2}{*}{ Gamma distribution } & Carriageway & 0.2954 & 0.0038 \\
\hline & & Passing lane & 0.4005 & 0.0149 \\
\hline \multirow{2}{*}{ Dense flow } & \multirow{2}{*}{ Gamma distribution } & Carriageway & 7.4072 & 3.5829 \\
\hline & & Passing lane & 7.7043 & 3.7311 \\
\hline
\end{tabular}

are used to simulate sparse flow and dense flow separately that can be loaded on both sides of the bridge simultaneously. The traffic condition is divided into sparse flow and dense flow that the headway of the former exceeds $3 \mathrm{~s}$ and that of the latter is less than $3 \mathrm{~s}$ [34]. Statistical analysis on the WIM data indicates that the vehicle headway of the dense and sparse flow obeys gamma distribution. The key parameters are shown in Table 4 . The corresponding vehicle headways are generated according to statistical properties. Figure 15 shows the vehicle headways of dense flow in passing lane. Then, combined with vehicle data, a bidirectional traffic flow with a dense upstream flow and a sparse downstream flow is formed to load on the bridge.

\section{FVD Effect under Traffic Flow}

According to existing research, the service life of bridge accessories, such as expansion joints and FVDs, is closely related to the deformation and fatigue properties of the components under external loads [35]. An accumulative friction slide distance that exceeds the design value is an important precipitating factor, and also it will lead to component damage in which traffic flow accounts for most of the accumulative displacement. Maximum girder displacement is a critical factor that determines whether the working condition of a bridge accessory is in the design range. Thus, the longitudinal accumulative girder displacement and maximum longitudinal girder displacement

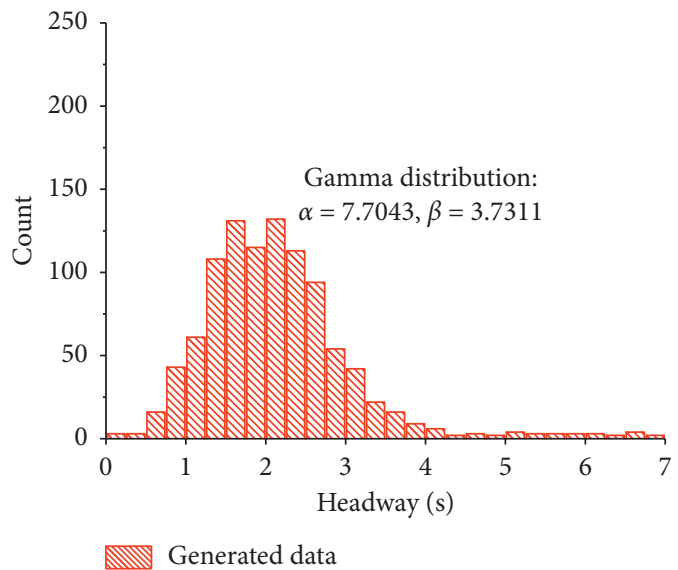

Figure 15: Vehicle headways of dense flow in passing lane.

are selected as the typical indexes of the vibration control effect of FVDs under traffic flow. In JT/T 926-2014, the damping velocity exponent is specified into seven classes $(0.1,0.2,0.3,0.4,0.5,0.6$, and 1$)$, and no limitation exists for the damping coefficient, whose value commonly ranges from $1000 \mathrm{kN} /(\mathrm{m} / \mathrm{s})^{\alpha}$ to $20000 \mathrm{kN} /(\mathrm{m} / \mathrm{s})^{\alpha}[13,27]$. The damping coefficient is set to $1000 \mathrm{kN} /(\mathrm{m} / \mathrm{s})^{\alpha}, 2500 \mathrm{kN} /(\mathrm{m} / \mathrm{s})^{\alpha}$, $5000 \mathrm{kN} /(\mathrm{m} / \mathrm{s})^{\alpha}, \quad 7000 \mathrm{kN} /(\mathrm{m} / \mathrm{s})^{\alpha}, \quad 10000 \mathrm{kN} /(\mathrm{m} / \mathrm{s})^{\alpha}$, $15000 \mathrm{kN} /(\mathrm{m} / \mathrm{s})^{\alpha}$, and $20000 \mathrm{kN} /(\mathrm{m} / \mathrm{s})^{\alpha}$ to analyze the FVDs' effects with representative combinations of parameters. 


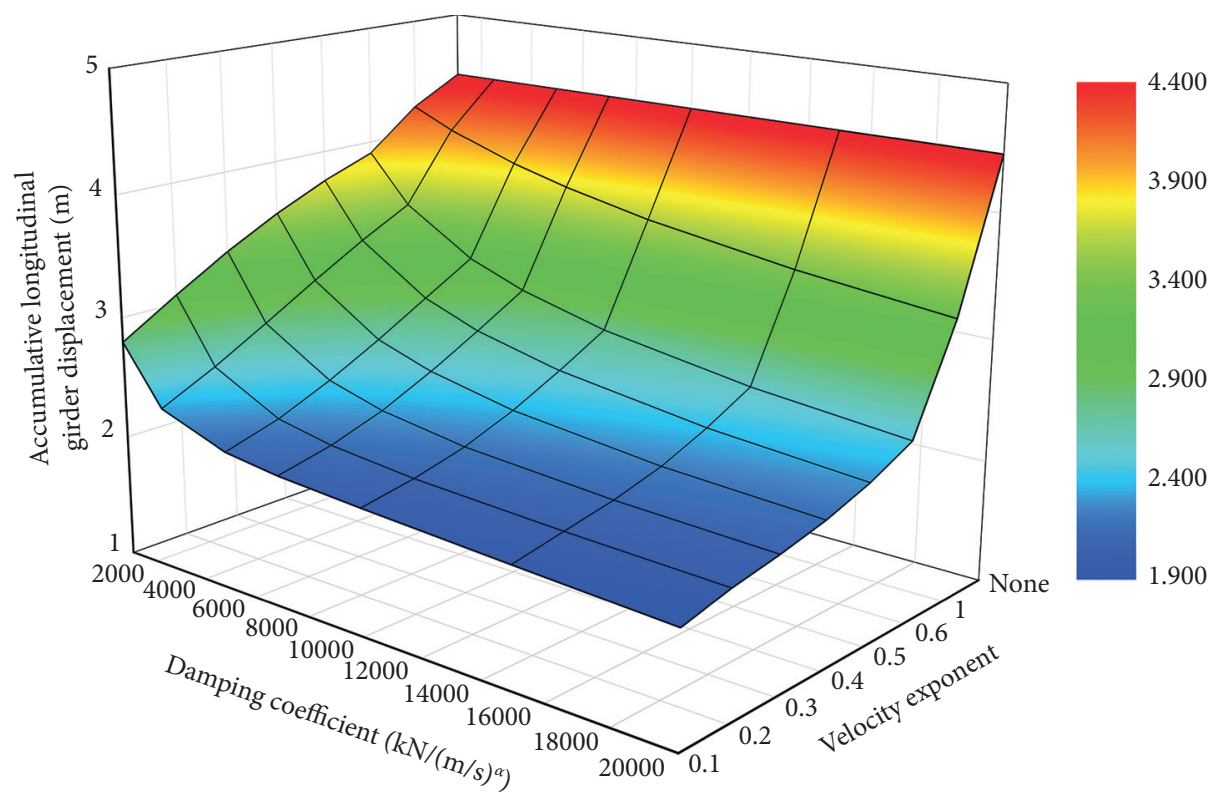

Figure 16: Accumulative longitudinal girder displacement $W_{\mathrm{gc}}$.

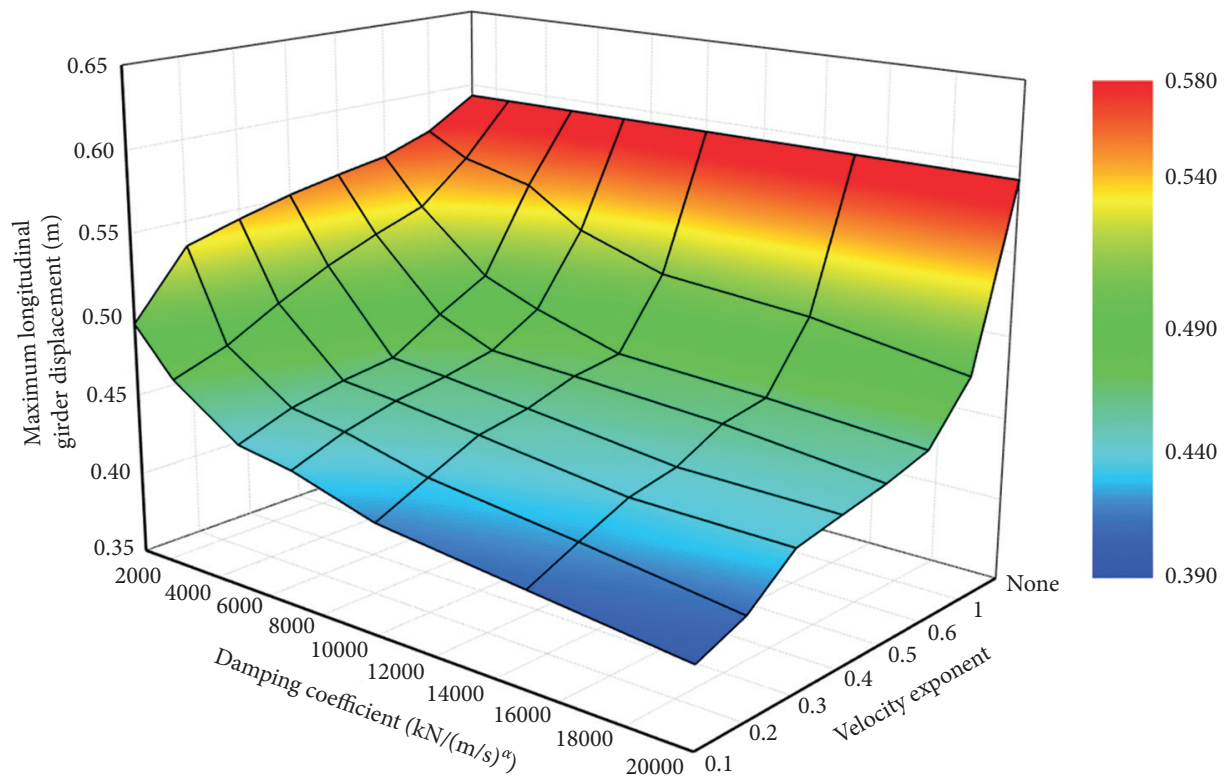

FIGURE 17: Maximum longitudinal girder displacement $W_{\mathrm{g} m}$.

Nonlinear time history analysis under traffic flow is conducted using the bridge-vehicle interaction system established in Section 2. The main girder of the suspension bridge is directly influenced by FVDs, so the girder response varies as shown in Figures 16-18. The installation of FVDs provides the following benefits: longitudinal displacement and accumulative displacement decrease noticeably with an enlargement in the damping coefficient and a decrease in the velocity exponent. The girder midspan bending moment also decreases with increased damping coefficient and decreased velocity exponent. When the velocity exponent exceeds 0.4 , the influence on girder midspan bending moment is not remarkable. But when the velocity exponent is below 0.4 and the damping coefficient exceeds $7000 \mathrm{kN} /(\mathrm{m} / \mathrm{s})^{\alpha}$, the girder midspan bending moment noticeably declines with increased damping coefficient and decreased velocity exponent.

Figures 19 and 20 show that the variation trend of longitudinal pylon displacement and acceleration increases accordingly with the increase in the velocity exponent or the decrease in the damping coefficient. Figure 21 shows that the variation trend of the pylon bending moment is relatively 


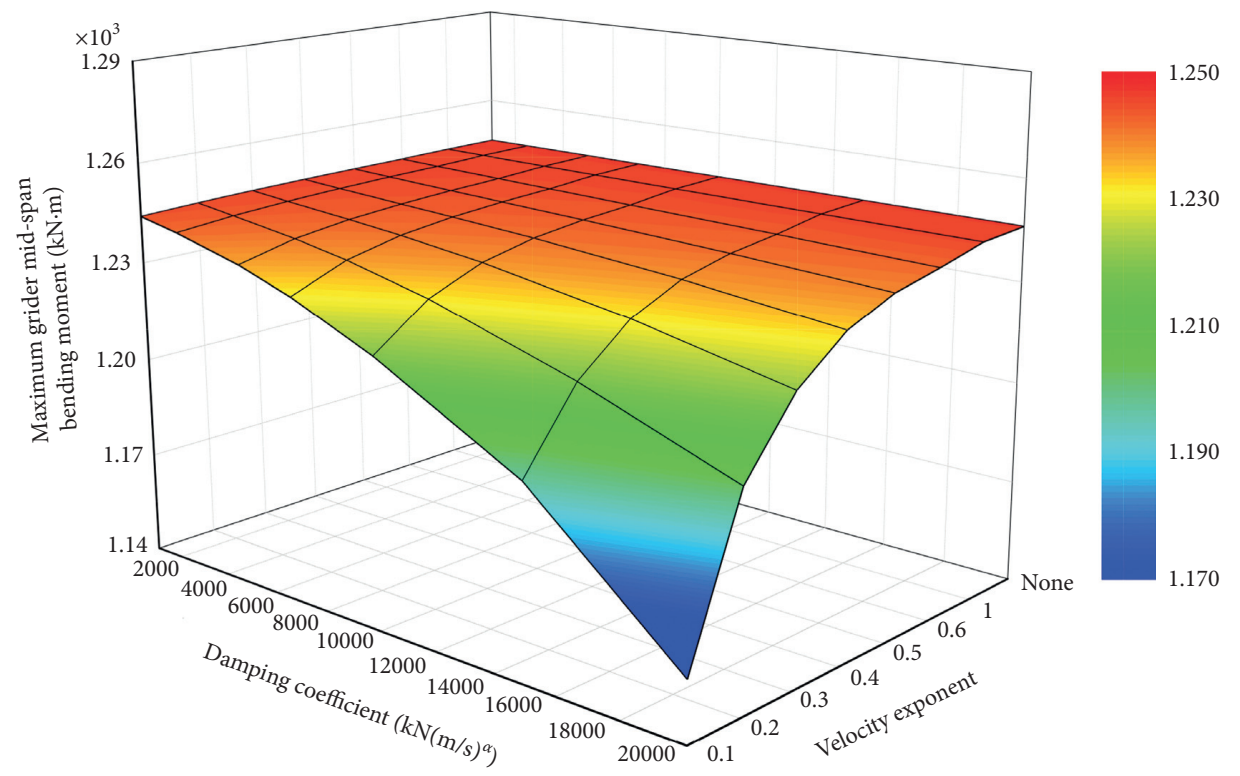

FIgURE 18: Maximum midspan girder bending moment $M_{g}$.

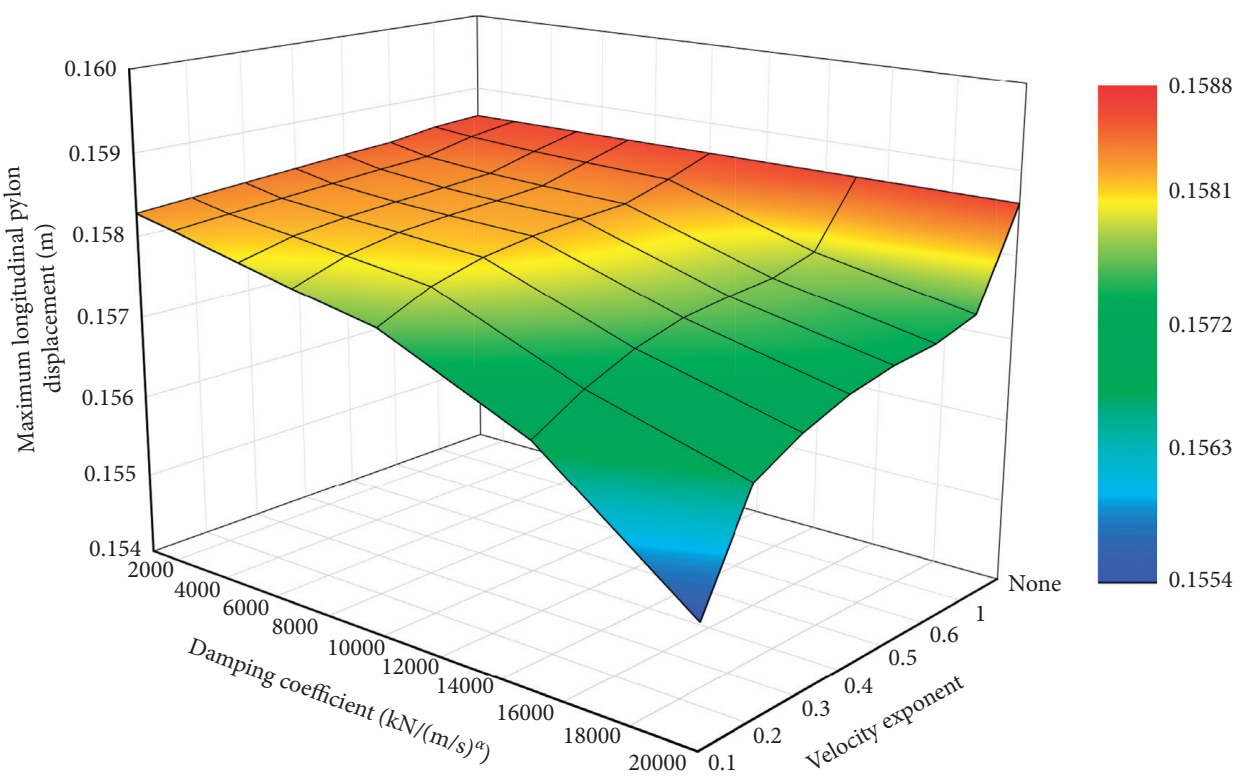

FIgURE 19: Maximum longitudinal pylon displacement $W_{t m}$.

complex; it increases with the damping coefficient when the velocity exponent $\alpha<0.3$ but decreases and then increases with increased damping coefficient when $0.3 \leq \alpha<1$.

Figure 22 shows that the suspender force is also influenced by FVDs, which is caused by the reciprocating motion of the main girder. The maximum suspender forces were induced by vehicles only; it may cause a relative displacement between the girder and the main cable. The changing law is similar to that of maximum longitudinal pylon displacement.

The extreme values of each index are shown in Table 5. The FVDs evidently influence the longitudinal girder displacement and pylon acceleration. The maximum control efficiency of the girder displacement reaches $33.67 \%$. The accumulated longitudinal girder displacement can be reduced by $57.71 \%$. These results mean that FVDs can remarkably decrease the daily reciprocating motion of related components. Although the maximum reduced rate of the pylon longitudinal displacement is only $2.02 \%$, the maximum pylon acceleration can be reduced by $31.51 \%$. The pylon bending moment and suspender force are less affected in that the maximum control efficiencies are less than $2 \%$.

Once the damping coefficient and velocity exponent are determined, the damping force under normal working 


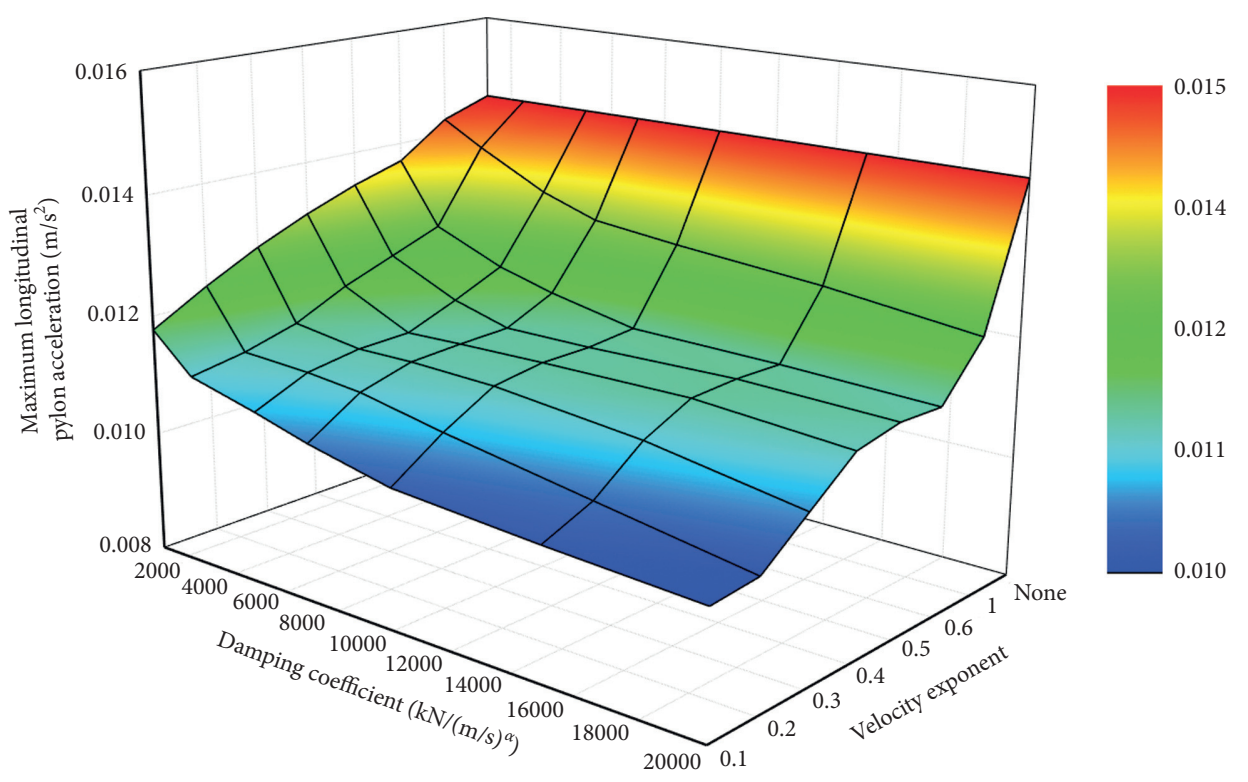

FIgURE 20: Maximum longitudinal pylon acceleration $a_{t}$.

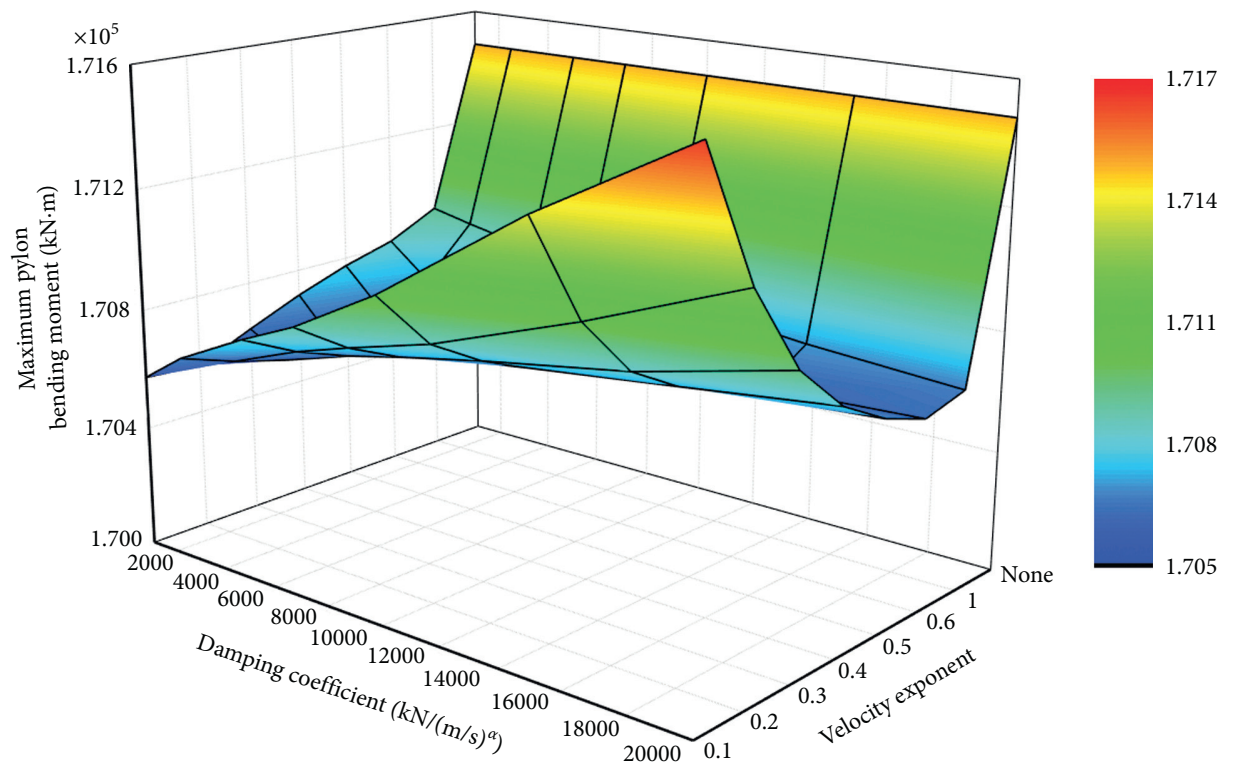

FIGURE 21: Maximum pylon bending moment $M_{t}$.

conditions can be calculated by (8) on the basis of the corresponding damping velocity shown in Figure 23. As shown in Figure 24, the damping force of a partial damping coefficient and velocity exponent is around or exceeds the specified value for a single FVD in Chinese standard [27]. The damping coefficient has an apparent influence on the damping force of the FVDs only when the velocity exponent is relatively small. Preceding results reveal that the longitudinal girder displacement is the most significant response of the structure, but its variation tendency is nonlinear. A large damping coefficient improves the FVD effects, but the effect of improvement is not proportional to the damping coefficient. An excessive damping coefficient brings increased damping force, so the design force of FVD must be high enough to burden the external load. Otherwise, the FVD would be working in limit state under the dense traffic flow, which is adverse to its durability.

By contrast, low velocity exponent results in an evident improvement, especially for FVD performance and girder displacement, thereby potentially making FVD a valid vibration mitigation device in daily operation. Figures 25 and 26 show the time history curves of the maximum girder displacement and accumulative girder displacement when the velocity exponent is 0.1 . The accumulative girder 


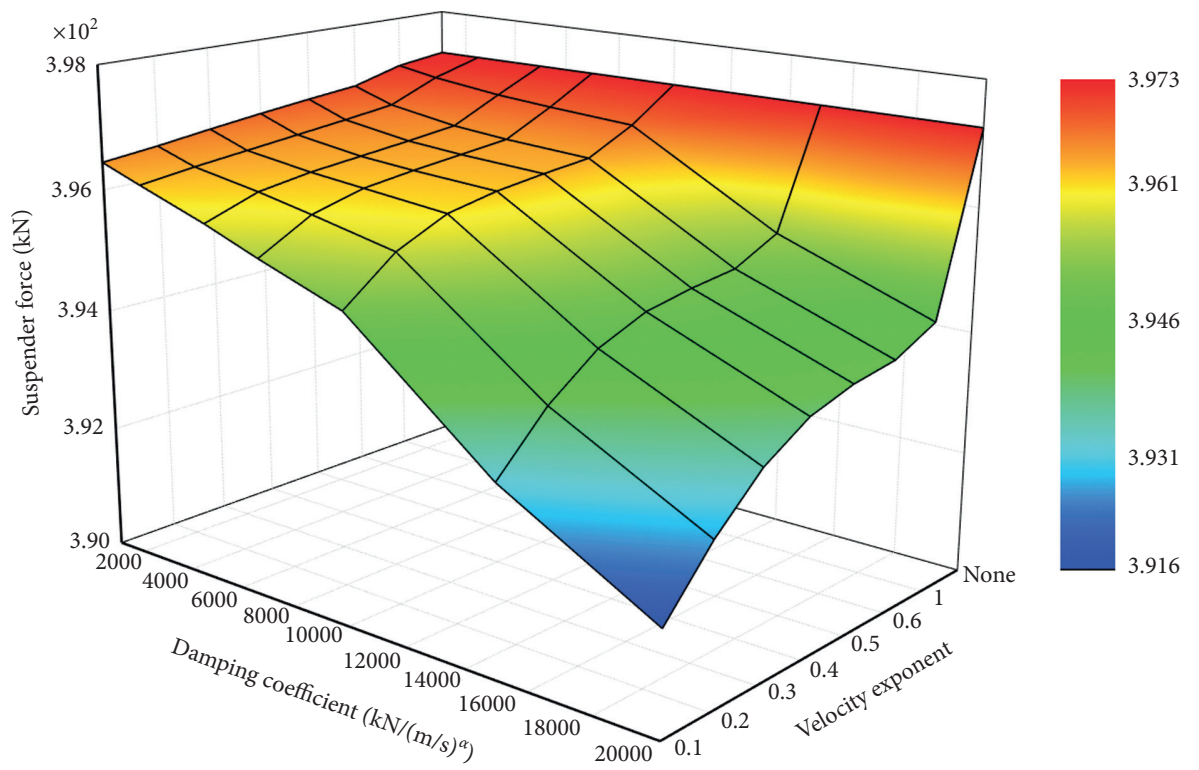

Figure 22: Maximum suspender force $F_{s}$.

TABle 5: Peak values of bridge dynamic response.

\begin{tabular}{lccccccc}
\hline & $W_{g m}(\mathrm{~m})$ & $W_{g c}(\mathrm{~m})$ & $M_{g}(\mathrm{kN} \cdot \mathrm{m})$ & $W_{t m}(\mathrm{~m})$ & $a_{t}\left(\mathrm{~m} / \mathrm{s}^{2}\right)$ & $M_{t}(\mathrm{kN} \cdot \mathrm{m})$ & $F_{s}(\mathrm{kN})$ \\
\hline Minimum value & 0.3931 & 1.8845 & 1157 & 0.1554 & 0.010 & 170548 \\
Maximum value & 0.5741 & 4.2352 & 1246 & 0.1586 & 0.0143 & 171652 \\
Without damper & 0.5926 & 4.4561 & 1246 & 0.1586 & 0.0146 & 171481 \\
Maximum control efficiency & 33.67 & 57.71 & 7.14 & 2.02 & 31.51 & 397.15 \\
\hline
\end{tabular}

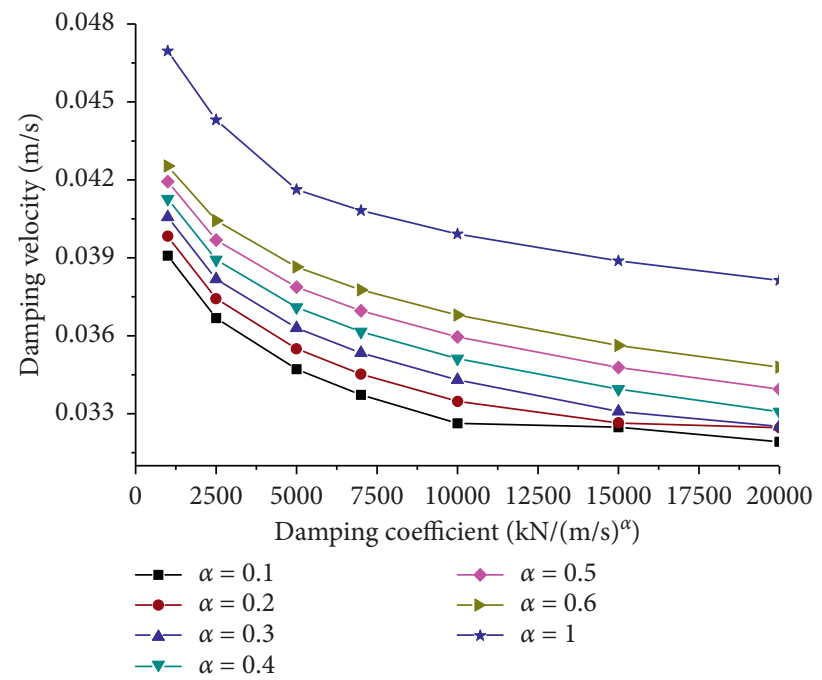

Figure 23: Maximum value of damping velocity $V_{c}$.

displacement decreases noticeably when the damping coefficient $C<5000 \mathrm{kN} /(\mathrm{m} / \mathrm{s})^{\alpha}$, but when the damping coefficient $C>5000 \mathrm{kN} /(\mathrm{m} / \mathrm{s})^{\alpha}$, the accumulative girder displacement decreases slightly with increased damping coefficient. The benefits of an excessive damping coefficient are not proportional to the costs of it.

But for the low velocity exponent, the manufacturing process of this type of FVD is complicated and its durability 


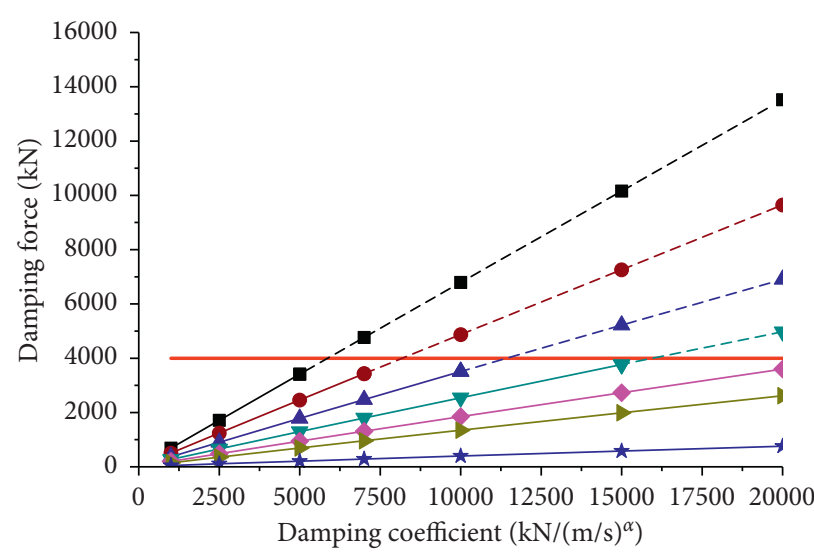

$$
\begin{array}{ll}
\rightarrow \alpha=0.1 & \longrightarrow \alpha=0.5 \\
-\alpha=0.2 & \rightarrow \alpha=0.6 \\
-\alpha \alpha=0.3 & \rightarrow \alpha=1 \\
\rightarrow \alpha=0.4 &
\end{array}
$$

Figure 24: Maximum value of damping force $F$.

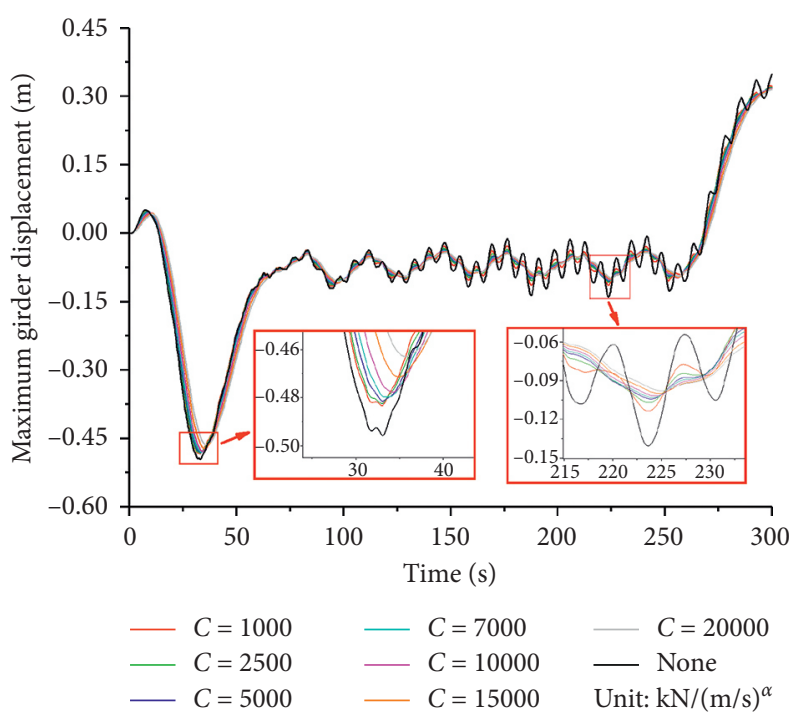

FIGURE 25: Time history curve of maximum girder displacement $(\alpha=0.1)$.

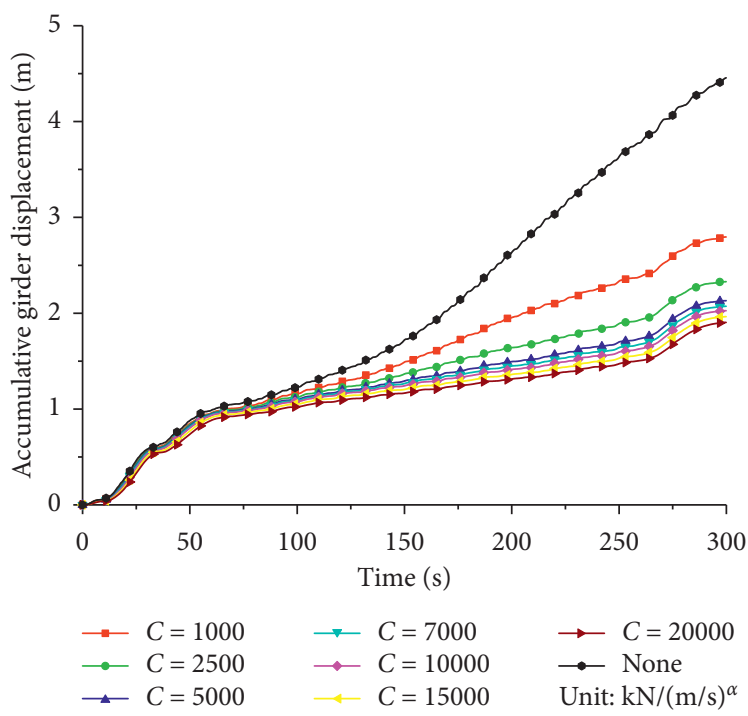

Figure 26: Time history curve of accumulative girder displacement $(\alpha=0.1)$. 


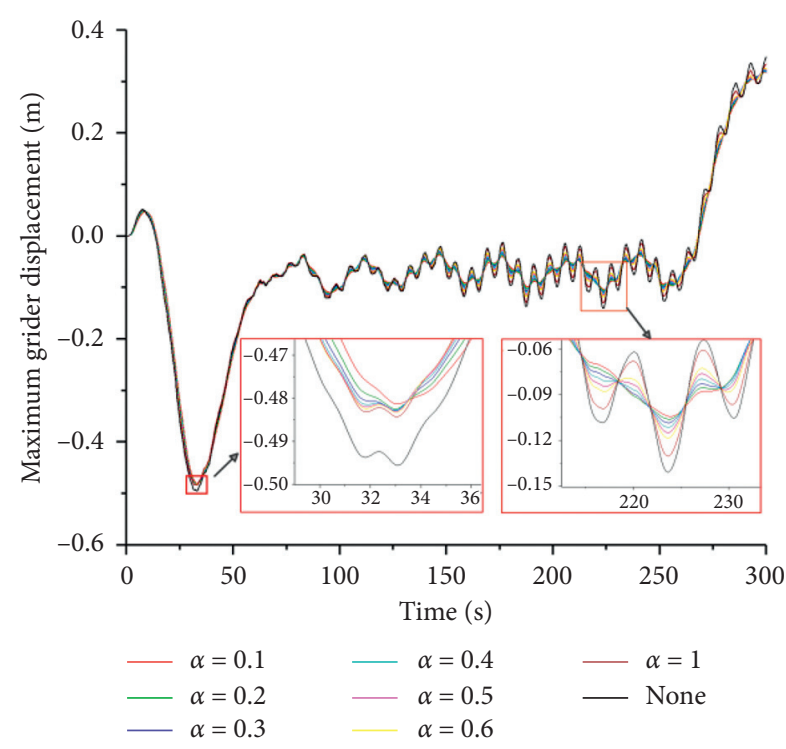

FIGURE 27: Time history curve of maximum girder displacement $\left(C=5000 \mathrm{kN} /(\mathrm{m} / \mathrm{s})^{\alpha}\right)$.

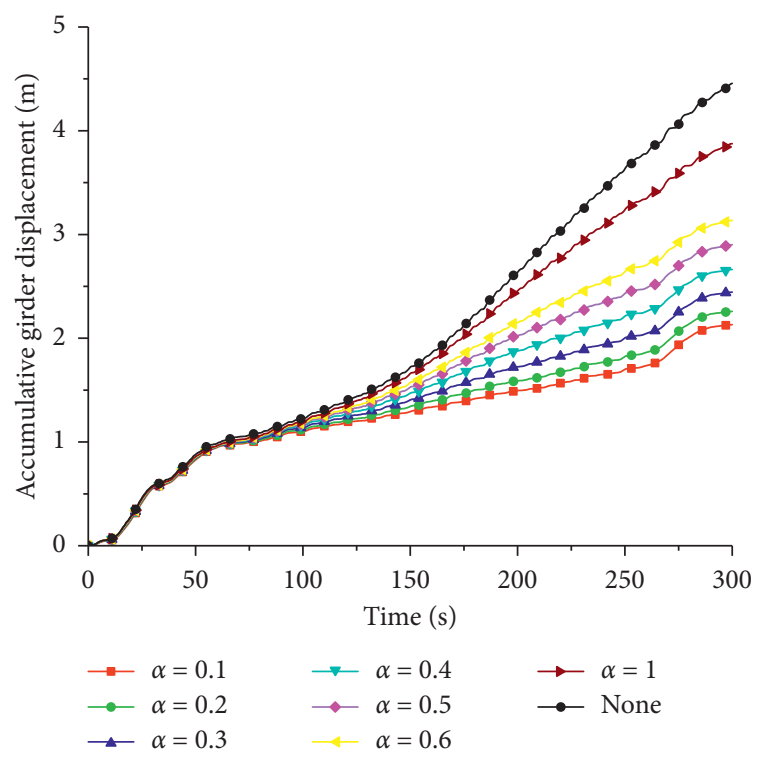

FIGURE 28: Time history curve of accumulative girder displacement $\left(C=5000 \mathrm{kN} /(\mathrm{m} / \mathrm{s})^{\alpha}\right)$.

may be limited. So the influence of the velocity exponent also is investigated. When the damping coefficient is $5000 \mathrm{kN} /(\mathrm{m} / \mathrm{s})^{\alpha}$, the time history curves of the maximum girder displacement and accumulative girder displacement are shown in Figures 27 and 28. It can be seen that the decreasing of velocity exponent has little influence on the maximum girder displacement while the common vibration is reduced. According to Figure 28, the accumulative girder displacement can be reduced obviously with the decreased velocity exponent. That is because traffic load is different from the seismic excitation which has the characteristics of short time but strong intensity. Traffic load is generally a low intensity but long term process. The low velocity exponent brings evident benefits for the bridge response under traffic flow.

According to the results, the damping coefficient $C>5000 \mathrm{kN} /(\mathrm{m} / \mathrm{s})^{\alpha}$ and the velocity exponent $\alpha=0.1$ are the best parameters for FVDs under traffic flow. The damping coefficient does not need to be too high. However, the FVDs application should consider a variety of factors, such as wind and earthquake. So if the velocity exponent has to be increased, combined with Figure 16, the benefit of low velocity exponent reduced when the damping coefficient is high enough and the damping coefficient can be enlarged to fit with the velocity exponent for the best effect of reducing the response under traffic flow.

\section{Conclusions}

In this study, bridge dynamic response with FVDs under traffic flow was analyzed on the basis of monitored data. For rapid analysis under high-intensity traffic flow, a bridgevehicle coupling method optimized by isoparametric mapping and improved binary search was developed and validated. Then, traffic data with extreme total vehicle weight in an hour were screened out from monitoring data to simulate traffic flow. Lastly, the simulation analysis of the bridge with FVDs under traffic flow based on monitored data was accomplished. Various indicators of the bridge are affected to different degrees by variations in the FVD parameters. The results show that vehicle-bridge coupling analysis method optimized by isoparametric mapping and improved binary search based on the interhistory method was validated. The method's findings were consistent with the experimental results; therefore, the proposed method can be used in vehicle-bridge coupling analysis under highintensity traffic flow.

For the prototype bridge, the results show that FVDs' settlement positively impacts bridge dynamic response under traffic flow. The traffic load should be considered in FVD design, as the dynamic response is remarkably influenced by FVD parameters. A reasonable FVD design can effectively reduce the accumulative longitudinal girder displacement, maximum longitudinal girder displacement, and longitudinal pylon acceleration whose maximum control efficiency, respectively, reaches $57.71 \%, 33.67 \%$, and $31.51 \%$, the girder bending moment also can decrease by $7.14 \%$, and the maximum control efficiencies of other indexes were less than $3 \%$.

This study also shows an increase in the damping coefficient and a decrease in the velocity exponent that can reduce the response of key indexes. However, an excessive damping coefficient will bring negligible improvement and may lead to high-intensity work under traffic flow, thereby adversely affecting component durability. A low velocity exponent will result in evident improvement, especially for FVD performance and girder displacement, and plays a role in maintaining low-velocity movement. The benefits of low velocity exponent reduced when the damping coefficient is high enough. When the velocity exponent has to be increased, the damping coefficient can be enlarged to fit with the velocity exponent. 
Note that the research and conclusions in this paper focus on the FVDs' influence on the bridge response under traffic flow. In a subsequent research program, FVDs effects on bridge dynamic response under the combined action of wind and traffic loads and the comprehensive optimization of FVD parameters will be investigated.

\section{Appendix}

$K_{v u L}^{i}$ and $K_{v u R}^{i}$ denote the vertical spring stiffness of the $i_{\text {th }}$ axle in upper suspension $(\mathrm{N} / \mathrm{m})$ :

$$
K_{v u L}^{i}=K_{v u R}^{i}
$$

$K_{y u L}^{i}$ and $K_{y u R}^{i}$ denote the lateral spring stiffness of the $i_{\text {th }}$ axle in upper suspension $(\mathrm{N} / \mathrm{m})$ :

$$
K_{y u L}^{i}=K_{y u R}^{i} .
$$

$K_{v l L}^{i}$ and $K_{v l R}^{i}$ denote the vertical spring stiffness of the $i_{\text {th }}$ axle in lower suspension $(\mathrm{N} / \mathrm{m})$ :

$$
K_{v l L}^{i}=K_{v l R}^{i} .
$$

$K_{y l L}^{i}$ and $K_{y l R}^{i}$ denote the lateral spring stiffness of the $i_{\text {th }}$ axle in lower suspension $(\mathrm{N} / \mathrm{m})$ :

$$
K_{y l L}^{i}=K_{y l R}^{i} .
$$

$C_{v u L}^{i}$ and $C_{v u R}^{i}$ denote the vertical damping of the $i_{t h}$ axle in upper suspension $(\mathrm{N} \cdot \mathrm{s} / \mathrm{m})$ :

$$
C_{v u L}^{i}=C_{v u R}^{i} .
$$

$C_{y u L}^{i}$ and $C_{y u R}^{i}$ denote the lateral damping of the $i_{t h}$ axle in upper suspension $(\mathrm{N} \cdot \mathrm{s} / \mathrm{m})$ :

$$
C_{y u L}^{i}=C_{y u R}^{i}
$$

$C_{v l L}^{i}$ and $C_{v l R}^{i}$ denote the vertical damping of the $i_{t h}$ axle in lower suspension $(\mathrm{N} \cdot \mathrm{s} / \mathrm{m})$ :

$$
C_{v l L}^{i}=C_{v l R}^{i} .
$$

$C_{y l L}^{i}$ and $C_{y l R}^{i}$ denote the lateral damping of the $i_{t h}$ axle in lower suspension $(\mathrm{N} \cdot \mathrm{s} / \mathrm{m})$ :

$$
C_{y l L}^{i}=C_{y l R}^{i} .
$$

$L_{i}$ denotes the distance from the center of mass of car body to the $i_{t h}$ axle.

$b_{1}$ denotes half of the lateral wheel spacing.

$h_{1}$ denotes the vertical distance from the center of mass of car body to the upper plane of the spring.

$h_{v}$ denotes the vertical distance from the center of mass of car body to road surface.

\section{Data Availability}

The raw/processed data required to reproduce these findings cannot be shared at this time as the data also form part of an ongoing study.

\section{Conflicts of Interest}

The authors declare that they have no conflicts of interest.

\section{Acknowledgments}

The authors appreciate the financial support of the National Natural Science Foundation of China (Grant no. 51878058) and the Fundamental Research Funds for the Central Universities (Grant no. 300102219402).

\section{References}

[1] I. D. Aiken and J. M. Kelly, "Cyclic dynamic testing of fluid viscous dampers," in Proceedings of the Caltrans fourth seismic research conference, pp. 1-9, Sacramento, CA, USA, July 1996.

[2] Z. H. Zhang, H. W. Zhou, and X. F. Wang, "Application and development of high efficiency viscous Damper on Egongyan Yangtze River suspension bridge in Chongqing," in Proceedings of the China Highway Society: Paper Collection of 2002 National Bridge Academic Conference of Bridge and Structural Engineering Branch of China Highway Society, pp. 470-477, Beijing, China, June 2002, in Chinese.

[3] F. Ferreira and L. Simões, "Optimum design of a controlled cable-stayed footbridge subject to a running event using semiactive and passive mass dampers," Journal of Performance of Constructed Facilities, vol. 33, no. 3, Article ID 04019025, 2019.

[4] J. Yi, J. Li, and Z. Guan, "Shake table studies on viscous dampers in seismic control of a single-tower cable-stayed bridge model under near-field ground motions," Journal of Earthquake and Tsunami, vol. 12, no. 5, Article ID 1850011, 2018.

[5] T. Guo, J. Liu, Y. F. Zhang, and S. J. Pan, "Displacement monitoring and analysis of expansion joints of long-span steel bridges with viscous dampers," Journal of Bridge Engineering, vol. 20, no. 9, Article ID 04014099, 2015.

[6] J. Zhong, Z. Hu, W. Yuan, and L. Chen, "System-based probabilistic optimization of fluid viscous dampers equipped in cable-stayed bridges," Advances in Structural Engineering, vol. 21, no. 12, pp. 1815-1825, 2018.

[7] J. S. Hwang and Y. S. Tseng, "Design formulations for supplemental viscous dampers to highway bridges," Earthquake Engineering \& Structural Dynamics, vol. 34, no. 13, pp. 1627-1642, 2010.

[8] Y. F. Huang, Y. Xu, and J. Z. Li, "Simplified parameter design method of viscous dampers for cable-stayed bridge under near-fault ground motions," China Civil Engineering Journal, vol. 49, no. 9, pp. 72-77, 2016, in Chinese.

[9] Z. X. Liu, T. Guo, L. Y. Huang, and Z. H. Pan, "Fatigue life evaluation on short suspenders of long-span suspension bridge with central clamps," Journal of Bridge Engineering, vol. 22, no. 10, Article ID 04017074, 2017.

[10] T. B. Wan, "Performance requirements of viscous dampers for improvement of durability of bridge structures," Bridge Construction, vol. 46, no. 4, pp. 29-34, 2016, in Chinese. 
[11] H. Xia, Y. L. Xu, and Q. S. Yan, "Dynamic response of long span suspension bridge to high wind and running train," Journal of the China Railway Society, vol. 24, no. 4, pp. 83-91, 2002, in Chinese.

[12] W. S. Han, H. J. Liu, D. H. Bao, P. M. Huang, and Y. G. Yuan, "Establishment and visualization of wind-vehicle-bridge analysis system for the large-span steel truss suspension bridge," China Civil Engineering Journal, vol. 51, no. 3, pp. 99-108, 2018, in Chinese.

[13] Z. Q. Wang, S. D. Wu, and L. C. Fan, "Research on viscous damper parameters of Donghai Bridge," China Journal of Highway and Transport, vol. 18, no. 3, 2005, in Chinese.

[14] Y. L. Ding, F. F. Geng, W. H. Ge, J. Y. Song, W. H. Li, and Y. Q. Wang, "Control of wind-induced buffeting responses of a multi-tower cable-stayed bridge using viscous dampers," Engineering Mechanics, vol. 32, no. 4, pp. 130-137, 2015, in Chinese.

[15] X. Z. Li, L. M. Zhang, and J. Zhang, "State of the art review and trend of studies on coupling vibration for vehicle and highway bridge system," Engineering Mechanics, vol. 25, no. 3, pp. 230-240, 2008, in Chinese.

[16] Q. L. Zou, L. Deng, T. D. Guo, and X. F. Yin, "Comparative study of different numerical models for vehicle-bridge interaction analysis," International Journal of Structural Stability and Dynamics, vol. 16, no. 9, pp. 1636-1643, 2016.

[17] ANSYS Inc., ANSYS 15.0, ANSYS Inc., Canonsburg, PA, USA, 2013.

[18] H. Wang and A. Q. Li, Finite Element Analysis and Engineering Examples of Long-Span Bridges, pp. 18-94, China Architechture publishing and Media Co., Ltd., Beijing, China, 2014, in Chinese.

[19] H. Wang, A. Li, R. Hu, and J. Li, "Accurate stress analysis on steel box girder of long span suspension bridges based on multi-scale submodeling method," Advances in Structural Engineering, vol. 13, no. 4, pp. 727-740, 2010.

[20] W. S. Han, L. Ma, and B. Wang, "Refinement analysis and dynamic visualization of traffic-bridge coupling vibration system," China Journal of Highway and Transport, vol. 26, no. 4, pp. 78-87, 2013, in Chinese.

[21] China Automobile Industry Corporation and China Automotive Technology and Research Center (CAIC-CATRC), Manual of Chinese Vehicle Type, Shandong Scientific and Technical Press, Shandong, China, 1993, in Chinese.

[22] T. L. Wang, M. Shahawy, and D. Z. Huang, "Dynamic response of highway trucks due to road surface roughness," Computers \& Structures, vol. 49, no. 6, pp. 1055-1067, 1993.

[23] X. S. Yi, J. G. Ren, and J. P. Zhou, "An accurately integrated 4node quadrilateral element," Journal of National University of Defense Technology, vol. 20, no. 1, pp. 1-4, 1998, in Chinese.

[24] International Organization for Standardization (ISO), $\mathrm{Me}$ chanical Vibration-Road Surface Profiles-Reporting of Measured Data (ISO 8608: 1995(E)), International Organization for Standardization (ISO), Geneva, Switzerland, 1995.

[25] N. Zhang, Y. Tian, and H. Xia, "A train-bridge dynamic interaction analysis method and its experimental validation," Engineering, vol. 2, no. 4, pp. 528-536, 2016.

[26] Mathworks Inc., MTLAB R2014a, Mathworks Inc., Natick, MA, USA, 2014.

[27] Ministry of Transport of the People's Republic of China (MTPR), Fluid Viscous Damper for Bridges (JT/T 926-2014), Ministry of Transport of the People's Republic of China (MTPR), Beijing, China, 2014, in Chinese.
[28] G. Y. Yang, Study on the Interaction of Vehicle Random Loads and Flexible Pavement, School of Civil Engineering, Central South University, Changsha, China, 2007, in Chinese.

[29] M. Huang, W. Guo, H. Zhu, and L. Li, "Dynamic test and finite element model updating of bridge structures based on ambient vibration," Frontiers of Architecture and Civil Engineering in China, vol. 2, no. 2, pp. 139-144, 2008.

[30] H. Wang, A. Q. Li, T. Guo, and T. Y. Tao, "Establishment and application of the wind and structural health monitoring system for the Runyang Yangtze River bridge," Shock \& Vibration, vol. 2014, Article ID 421038, 15 pages, 2014.

[31] W. S. Han, Visualized Simulation and Safety Evaluation of Heavy Traffic Dynamic Bridge, China communication press, Beijing, China, 2016, in Chinese.

[32] W. S. Han, X. D. Liu, G. Z. Gao, and Q. Xie, "Site-specific extra-heavy truck load characteristics and bridge safety assessment," Journal of Aerospace Engineering, vol. 31, no. 6, Article ID 04018098, 2018.

[33] J.-L. Martin, "Relationship between crash rate and hourly traffic flow on interurban motorways," Accident Analysis \& Prevention, vol. 34, no. 5, pp. 619-629, 2002.

[34] Ministry of Transport of the People's Republic of China (MTPR), Unified Standard for Reliability Design of Highway Engineering Structures (GB/T 50283-1999), Ministry of Transport of the People's Republic of China (MTPR), Beijing, China, 1999, in Chinese.

[35] Z. Sun and Y. F. Zhang, "Failure mechanism of expansion joints in a suspension bridge," Journal of Bridge Engineering, vol. 21, no. 10, Article ID 05016005, 2016. 